\title{
BACTERIOLOGICAL SAFETY OF SUYA, A READY-TO-EAT BEEF PRODUCT, AND ITS ASSOCIATION WITH ANTIBIOTIC-RESISTANT PATHOGENS IN NIGERIA
}

\author{
Temitope Kudirat Bello ${ }^{1}$ and Olorunjuwon Omolaja Bello ${ }^{2}$ \\ ${ }^{1}$ Department of Biological Sciences, Southwestern University, Ogun State, Nigeria \\ ${ }^{2}$ Department of Biological Sciences, University of Medical Sciences, Ondo City, Nigeria \\ \obello@unimed.edu.ng \\ https://doi.org/10.34302/crpjfst/2020.12.5.6 \\ Article history: \\ Received: \\ 28 August 2020 \\ Accepted: \\ 25 December 2020 \\ Keywords: \\ Antibiotic \\ resistance;Bacteria; \\ Drugs; \\ Food pathogens; \\ Ready-to-eat.

\begin{abstract}
The rapid development antibiotic-resistant food pathogens pose a heightened threat to public health. This study investigated the antibiotic resistance pattern of bacteria associated with suya meat, a ready-to-eat beef product, in Nigeria. Three hundred suya meat samples were cultured and pure isolates identified by API 20E and API 20NE. The resistance profile of isolates was determined using disc diffusion methods. Data were analysed by one-way analysis of variance and students' T-tests. The mean total plate counts (TPCs) of samples ranged from $1.0 \times 10^{5}$ to $3.7 \times 10^{5}$ $\mathrm{CFU} / \mathrm{g}$. There were no significant differences among the TPCs from zones A, B, C and D $(P>0.05)$. A total of 1014 isolates were obtained with Pseudomonas aeruginosa (13.51\%) having the highest percentage occurrence and Salmonella enteric Typhimurium $(1.48 \%)$, the lowest. A $92.90 \%$ portion of the isolates showed sensitivity to imipenem while $86.69 \%$ exhibited resistance to teicoplanin. This study revealed that the microbial quality of the ready-to-eat suya was at a borderline with reference to the microbiological guidelines for ready-to-eat animal food product. The study also revealed the presence of antibiotic-resistant bacteria in the ready-to-eat beef product which indicates a risk in food safety and a threat to public health. These findings will aid in the selection process of the right antibiotics in the treatment of food-borne infections while establishing the need for improvement on the microbial quality of the food product.
\end{abstract}

\section{Introduction}

Suya is a ready-to-eat spicy, barbecued, smoked or roasted meat. Its origin can be traced to the Hausa people of northern Nigeria, SubSaharan Africa, where their main occupation is rearing of cattle and growing of cash crops (Orogu and Oshilim, 2017). Thus, it is an important preoccupation and a major source of livelihood for the people. This generated the production of different types of beef products such as kundi, kilishi, balangu and suya, which are very popular protein-rich foods (Olayinka and Sani, 2014). However, suya is the most popular, as it is consumed in other parts of the country (El-Hassan et al., 2018). In the recent days, suya vendors are found in almost every nook and cranny of towns and cities with their grill stands, and are being patronized from midday to late at night. It has gradually made its way into elite circles where it has become a delicacy served at parties and other social events.

Spices such as ginger, salt, peanut cake, and other seasonings, are usually used to marinate the thinly spliced meat, and then barbecued (Egbebi and Seidu, 2011). Dried pepper mixed with spices, and sliced onions could also be added when served this delicacy. 
The suya marinade is composed of complex mixture of additives and spices but there is no standard recipe for its production. The composition and types of ingredients vary from individual to individual, and according to regional preferences (Nwakanma et al., 2015; Amadi et al., 2016). However, the idea of requesting for only suya meat without the addition of the spices is becoming popular in the country. The reasons for this vary among individuals. Some simply prefer the taste of suya meat to having the spices sprinkled on it.

Barber et al. (2018) reported that there was an increased occurrence of disease outbreak caused by pathogenic and spoilage microorganisms in foods. The importance of foodborne diseases as a public health problem is often overlooked because their true incidence is difficult to evaluate and the severity of their health and economic impact is often not fully understood (Hassan et al., 2014). Bacteria are considered the most common cause of foodborne illness representing two-thirds of foodborne disease outbreaks and wide variety of microbes with much common and less specific clinical symptoms (Bello et al., 2019).

The rapid development of multidrug resistance in microorganisms has become an increasingly emerging problem with serious consequences on public health (WHO, 2014). The resistance of bacteria to commonly prescribed antimicrobial agents are associated with increasing treatment failures, and which could be explained by the high frequency with which antimicrobials are used empirically to treat diseases (Ikechukwu et al., 2019). This implies that as resistant pathogens develop and spread, the effectiveness of the antibiotics diminishes. The aim of this study, therefore, was to investigate the antibiotic resistance profiles of bacteria of clinical importance associated with ready-to-eat suya in Nigeria.

\section{Materials and methods}

\subsection{Study Area}

Ogun State is a state in southwestern Nigeria. The estimated population is 5,217,716 according to the National Population
Commission (NPC) and the National Bereau of Statistics (NBS) in 2013. The four geopolitical zones in Ogun State which include Yewa, Egba, Remo and Ijebu zones were the areas in which samplings were done.

\subsection{Processing of suya meat}

Sixty sticks of suya were personally prepared under aseptic conditions in accordance with standard procedures to serve as the control using beef. Putting all necessary precautions into consideration, meat samples were sliced into thin sheets and were inserted onto the suya sticks. Each stick of meat was pressed on the already prepared ingredient spread on a flat tray in order that the ingredient is evenly soaked into it. Groundnut oil was then sprinkled on the well-labeled sticks of meat before roasting was carried out.

\subsection{Collection of suya meat samples}

Two hundred and forty suya meat samples were purchased from different areas in the four geopolitical zones (Yewa, Egba, Remo and Ijebu zones) of Ogun State. Sixty suya samples from each of the four zones $(60 \times 4=240)$ were purchased from six different spots from ten different areas. The samples were collected and kept in refrigerator at $4{ }^{\circ} \mathrm{C}$ overnight to prevent contamination (as samples were purchased at night) and then transported to the laboratory for microbial analyses. Laboratory-based suya was prepared as a control each time suya meat samples were analysed in the laboratory, which summed up to 60 times. Invariably, a total of 300 suya samples were investigated in this study (Apata et al., 2013). For the purpose of this study, Yewa, Egba, Remo and Ijebu zones were labeled zones A, B, C and D, respectively while the samples prepared in the laboratory served as control.

\subsection{Roasting of suya meat}

Labeled stick meats were arranged round a glowing smokeless fire made from charcoal. The sticked meats were allowed to stay on the fire for $20 \mathrm{~min}$ with the distance of $22-23 \mathrm{~cm}$ from the centre of fire and intermittent turning 
of the product. Groundnut oil was intermittently sprinkled while the meat was being roasted.

\subsection{Cultivation of bacteria from suya meat}

The microbiological analysis of suya meat was carried out as described by American Public Health Association (APHA, 1992) and Association of Official Analytical Chemist (AOAC, 2000). Ten grams each of suya samples were blended using a disinfected blender (model 242 NAKAI, JAPAN) with 90 $\mathrm{ml}$ of $0.1 \%(\mathrm{~W} / \mathrm{V})$ peptone water for $60 \mathrm{~s}$ and serial dilutions made in $0.1 \%$ peptone water $(\mathrm{W} / \mathrm{V})$ to obtain up to $10^{-5}$ dilution factor while $0.1 \mathrm{ml}$ portion of each of the diluted samples was taken and dispensed in sterile Petri dishes containing appropriate agar medium using the spread plate method. Plate count agar (PCA) (Difco, USA) was employed for the determination of total bacterial count; violet red bile agar (VRBA) (Difco, USA) for total coliform.

Specific coliform organisms were differentiated by IMViC tests. Eosin methylene blue (EMB) agar (Oxoid, England) was used for the cultivation of Escherichia coli and Enterobacter aerogenes. For the isolation and enumeration of Salmonella, pre-enrichment was carried out using lactose broth incubated at $37{ }^{\circ} \mathrm{C}$ for $24 \mathrm{hrs}$. Ten (10) $\mathrm{ml}$ of pre-enriched medium was, under aseptic condition, pipetted and tranferred into $100 \mathrm{ml}$ sterile Tetrathionate broth (Hi-media laboratories, India) incubated at $37{ }^{\circ} \mathrm{C}$ for $24 \mathrm{hrs}$. The resultant broth was streaked onto three Salmonella differential media which were brilliant green phenol lactose agar (Difco, USA), Bismuth sulphate agar (Difco, USA) and deoxycholate citrate agar (Oxoid, England).

For the identification of Staphylococcus aureus and micrococci, the sample was inoculated onto nutrient broth at $37{ }^{\circ} \mathrm{C}$ for 24 hours after which it was plated onto mannitol salt agar. Colony forming units were counted and were expressed in $\log 10 \mathrm{cfu} / \mathrm{g}$ of samples. The microbiological guidelines for ready-to-eat food products are given in Table 1 .

Table 1.Microbiological Guidelines for Ready-to-eat Food Products

\begin{tabular}{|l|l|l|}
\hline Grades & TVC (total viable count) $/ \mathrm{g}$ at $30^{\circ} \mathrm{C}$ & Description \\
\hline I & $<10^{5}$ & Satisfactory \\
\hline II & $10^{5}-<10^{7}$ & Borderline \\
\hline III & $\geq 10^{7}$ & Unsatisfactory \\
\hline
\end{tabular}

Center for Food Safety (2014).

\subsection{Identification of bacterial isolates}

Pure isolates on agar plates were characterized by initial morphological examination of the distinct colonies. The biochemical tests included catalase test, coagulase test, citrate utilization test, oxidase test, triple sugar iron agar, urease test, sugar fermentation test, methyl red test and indole production test (Cowan and Steel, 1985). Salmonella serotyping was by slide agglutination (Kauffmann-White-Le Minor scheme) based on the agglutination of bacteria with specific sera to identify variants of the somatic (O) and flagellar (H) antigens (Grimont and Weill, 2007; Guibourdenche et al., 2010). Specific identification of the other isolates was performed using the API $20 \mathrm{E}$ and API 20NE for confirmation of members of Enterobacteriaceae and nonEnterobacteriaceae, respectively.

\subsection{Determination of antibiotic sensitivity of bacterial isolates}

The disc diffusion assay was employed to investigate the sensitivity of isolates to the antibiotics (Clinical and Laboratory Standards Institute, CLSI, 2016). The standardized inocula of the test organisms were emulsified on the surface of Mueller Hinton Agar (Oxoid, England) using sterile cotton swab (220210 BD 
SWUBE, India), and the plates was dried at room temperature for $5 \mathrm{~min}$, and then incubated at $30{ }^{\circ} \mathrm{C}$ for 48 hours (Center for Food Safety, 2014). A total of 18 antibiotics representing 12 antibiotic classes were investigated against isolates from the suya samples.

The antibiotics investigated were Tetracycline $(0.002-32 \mathrm{mg} / \mathrm{L})$, Doxycycline $(0.002-32 \mathrm{mg} / \mathrm{L}), \quad$ Minocycline $(0.002-32$ $\mathrm{mg} / \mathrm{L})$, Erythromycin (0.016-256 $\mathrm{mg} / \mathrm{L})$, Colistin (0.064-1024 mg/L), Chloramphenicol $(0.016-256 \mathrm{mg} / \mathrm{L})$,

Trimethoprim/ Sulfamethoxazole $\quad(0.002-32 \quad \mathrm{mg} / \mathrm{L})$, Gentamicin (0.016-256 mg/L), Rifampicin (0.002-32 mg/L), Nalidixic acid (0.016-256 $\mathrm{mg} / \mathrm{L})$, Ciprofloxacin (0.002-32 $\mathrm{mg} / \mathrm{L})$, Penicillin G $(0.002-32 \mathrm{mg} / \mathrm{L})$, Ampicillin (0.016-256 $\mathrm{mg} / \mathrm{L})$, Imipenem (0.002-32 $\mathrm{mg} / \mathrm{L})$ Cefalotin (0.016-256 $\mathrm{mg} / \mathrm{L})$, Ceftriaxone (0.016-256 mg/L), Teicoplanin (0.016-256 mg/L) and Vancomycin (0.016$256 \mathrm{mg} / \mathrm{L})$. A phase-contrast microscope with objective E.10 0.25 160/- (Nikon, France) was used (100× magnification) to read the limit of growth inhibition.

\subsection{Data Analysis}

Data were collated and statistically analysed using MedCalc statistical software, version 17.2. Simple means, percentages and frequencies from different locations were computed and compared using One-way
Analysis of Variance (ANOVA) and independent T-test. Data were presented as mean \pm standard error (SE) of triplicate data. The significance was determined at 95\% level of confidence $(P \leq 0.05)$.

\section{Results and Discussions}

\subsection{Mean total bacterial counts from suya samples}

Each value $(1-10)$ in each zone represents mean of data obtained from six different suya spots in same area. The mean total plate count (TPC) from zones A, B, C and D ranged from $1.4 \times 10^{5}$ to $3.5 \times 10^{5} \mathrm{CFU} / \mathrm{g}, 1.1 \times 10^{5}$ to $3.5 \times$ $10^{5} \mathrm{CFU} / \mathrm{g}, 1.0 \times 10^{5}$ to $3.1 \times 10^{5} \mathrm{CFU} / \mathrm{g}$ and 1.0 $\mathrm{x} 10^{5}$ to $3.7 \times 10^{5}$, respectively. The total Enterobacteriaceae counts (TECs) ranged from $1.0 \times 10^{3}$ to $2.3 \times 10^{3} \mathrm{CFU} / \mathrm{g}, 1.5 \times 10^{3}$ to $2.1 \times$ $10^{3} \mathrm{CFU} / \mathrm{g}, 1.1 \times 10^{3}$ to $2.5 \times 10^{3} \mathrm{CFU} / \mathrm{g}$ and 1.0 $\mathrm{x} 10^{3}$ to $2.5 \times 10^{3} \mathrm{CFU} / \mathrm{g}$ as obtained in zones A, B, C and D, respectively. Total Staphylococcus count (TSCs) of suya samples ranged from $1.1 \times 10^{2}$ to $3.1 \times 10^{2} \mathrm{CFU} / \mathrm{g}, 1.1 \mathrm{x}$ $10^{2}$ to $3.0 \times 10^{2} \mathrm{CFU} / \mathrm{g}, 1.0 \times 10^{2}$ to $3.1 \times 10^{2}$ $\mathrm{CFU} / \mathrm{g}$ and $1.0 \times 10^{2}$ to $2.2 \times 10^{2} \mathrm{CFU} / \mathrm{g}$ as encountered in zones $\mathrm{A}, \mathrm{B}, \mathrm{C}$ and $\mathrm{D}$, respectively. There were no significant differences among the bacterial counts from zones $\mathrm{A}, \mathrm{B}, \mathrm{C}$ and $\mathrm{D}(P>0.05)$ but values showed statistical differences from the control $(P<0.05)$ (Table 2).

Table 2. Mean total bacterial counts from suya samples in Nigeria

\begin{tabular}{|l|l|l|l|l|}
\hline Zone & Area & $\begin{array}{l}\text { Total plate count } \\
(\mathrm{TPC})(\mathrm{CFU} / \mathrm{g})\end{array}$ & $\begin{array}{l}\text { Total Enterobacteria } \\
\text { count }(\mathrm{TEC})(\mathrm{CFU} / \mathrm{g})\end{array}$ & $\begin{array}{l}\text { Total Staphylococcus } \\
\text { count }(\mathrm{TSC})(\mathrm{CFU} / \mathrm{g})\end{array}$ \\
\hline \multirow{4}{*}{$\mathrm{A}$} & $\mathrm{A}_{1}$ & $1.9 \times 10^{5}$ & $2.3 \times 10^{3}$ & $1.2 \times 10^{2}$ \\
\cline { 2 - 5 } & $\mathrm{A}_{2}$ & $3.5 \times 10^{5}$ & $1.0 \times 10^{3}$ & $1.7 \times 10^{2}$ \\
\cline { 2 - 5 } & $\mathrm{A}_{3}$ & $2.3 \times 10^{5}$ & $2.2 \times 10^{3}$ & $2.1 \times 10^{2}$ \\
\cline { 2 - 5 } & $\mathrm{A}_{4}$ & $2.5 \times 10^{5}$ & $2.1 \times 10^{3}$ & $1.8 \times 10^{2}$ \\
\cline { 2 - 5 } & $\mathrm{A}_{5}$ & $2.1 \times 10^{5}$ & $1.8 \times 10^{3}$ & $3.1 \times 10^{2}$ \\
\cline { 2 - 5 } & $\mathrm{A}_{6}$ & $1.7 \times 10^{5}$ & $1.6 \times 10^{3}$ & $2.2 \times 10^{2}$ \\
\cline { 2 - 5 } & $\mathrm{A}_{7}$ & $1.4 \times 10^{5}$ & $1.8 \times 10^{3}$ & $2.1 \times 10^{2}$ \\
\cline { 2 - 5 } & $\mathrm{A}_{8}$ & $1.8 \times 10^{5}$ & $2.3 \times 10^{3}$ & $1.4 \times 10^{2}$ \\
\cline { 2 - 5 } & $\mathrm{A}_{9}$ & $2.6 \times 10^{5}$ & $2.1 \times 10^{3}$ & $1.1 \times 10^{2}$ \\
\cline { 2 - 5 } & $\mathrm{A}_{10}$ & $2.0 \times 10^{5}$ & $1.4 \times 10^{3}$ & $1.86 \times 10^{2} \mathrm{c}$ \\
\cline { 2 - 5 } & Mean of means & $2.18 \times 10^{5 \mathrm{a}}$ & $1.86 \times 10^{3 \mathrm{~b}}$ & \\
\hline
\end{tabular}


Bello and Bello/Carpathian Journal of Food Science and Technology, Special Issue 2020, 12(5), 81-98

\begin{tabular}{|c|c|c|c|c|}
\hline \multirow[t]{11}{*}{$\mathrm{B}$} & $\mathrm{B}_{1}$ & $2.7 \times 10^{5}$ & $1.7 \times 10^{3}$ & $1.5 \times 10^{2}$ \\
\hline & $\mathrm{B}_{2}$ & $1.3 \times 10^{5}$ & $1.5 \times 10^{3}$ & $3.0 \times 10^{2}$ \\
\hline & $\mathrm{B}_{3}$ & $1.1 \times 10^{5}$ & $2.0 \times 10^{3}$ & $2.2 \times 10^{2}$ \\
\hline & $\mathrm{B}_{4}$ & $1.9 \times 10^{5}$ & $1.8 \times 10^{3}$ & $1.5 \times 10^{2}$ \\
\hline & $\mathrm{B}_{5}$ & $2.4 \times 10^{5}$ & $1.7 \times 10^{3}$ & $1.1 \times 10^{2}$ \\
\hline & $\mathrm{B}_{6}$ & $2.9 \times 10^{5}$ & $1.5 \times 10^{3}$ & $1.3 \times 10^{2}$ \\
\hline & $\mathrm{B}_{7}$ & $2.1 \times 10^{5}$ & $2.0 \times 10^{3}$ & $1.2 \times 10^{2}$ \\
\hline & $\mathrm{B}_{8}$ & $3.5 \times 10^{5}$ & $2.1 \times 10^{3}$ & $2.1 \times 10^{2}$ \\
\hline & $\mathrm{B}_{9}$ & $2.3 \times 10^{5}$ & $1.9 \times 10^{3}$ & $1.3 \times 10^{2}$ \\
\hline & $\mathrm{B}_{10}$ & $2.2 \times 10^{5}$ & $1.5 \times 10^{3}$ & $1.2 \times 10^{2}$ \\
\hline & Mean of means & $2.24 \times 10^{5 \mathrm{a}}$ & $1.77 \times 10^{3 \mathrm{~b}}$ & $1.64 \times 10^{2 \mathrm{c}}$ \\
\hline \multirow[t]{11}{*}{$\mathrm{C}$} & $\mathrm{C}_{1}$ & $3.1 \times 10^{5}$ & $1.7 \times 10^{3}$ & $1.2 \times 10^{2}$ \\
\hline & $\mathrm{C}_{2}$ & $2.1 \times 10^{5}$ & $1.2 \times 10^{3}$ & $1.8 \times 10^{2}$ \\
\hline & $\mathrm{C}_{3}$ & $1.2 \times 10^{5}$ & $2.3 \times 10^{3}$ & $1.6 \times 10^{2}$ \\
\hline & $\mathrm{C}_{4}$ & $1.6 \times 10^{5}$ & $1.6 \times 10^{3}$ & $2.1 \times 10^{2}$ \\
\hline & $\mathrm{C}_{5}$ & $1.0 \times 10^{5}$ & $2.1 \times 10^{3}$ & $2.2 \times 10^{2}$ \\
\hline & $\mathrm{C}_{6}$ & $1.3 \times 10^{5}$ & $2.5 \times 10^{3}$ & $1.7 \times 10^{2}$ \\
\hline & $\mathrm{C}_{7}$ & $1.7 \times 10^{5}$ & $1.3 \times 10^{3}$ & $2.1 \times 10^{2}$ \\
\hline & $\mathrm{C}_{8}$ & $2.5 \times 10^{5}$ & $1.1 \times 10^{3}$ & $1.6 \times 10^{2}$ \\
\hline & $\mathrm{C}_{9}$ & $2.7 \times 10^{5}$ & $1.8 \times 10^{3}$ & $1.1 \times 10^{2}$ \\
\hline & $\mathrm{C}_{10}$ & $1.4 \times 10^{5}$ & $1.6 \times 10^{3}$ & $1.0 \times 10^{2}$ \\
\hline & Mean of means & $1.72 \times 10^{5 \mathrm{a}}$ & $1.72 \times 10^{3 \mathrm{a}}$ & $1.64 \times 10^{2 b}$ \\
\hline \multirow[t]{11}{*}{ D } & $D_{1}$ & $2.5 \times 10^{5}$ & $1.4 \times 10^{3}$ & $2.1 \times 10^{2}$ \\
\hline & $D_{2}$ & $2.3 \times 10^{5}$ & $1.9 \times 10^{3}$ & $1.9 \times 10^{2}$ \\
\hline & $D_{3}$ & $1.9 \times 10^{5}$ & $1.5 \times 10^{3}$ & $2.0 \times 10^{2}$ \\
\hline & $\mathrm{D}_{4}$ & $1.0 \times 10^{5}$ & $2.5 \times 10^{3}$ & $1.3 \times 10^{2}$ \\
\hline & $D_{5}$ & $3.7 \times 10^{5}$ & $1.0 \times 10^{3}$ & $2.1 \times 10^{2}$ \\
\hline & $\mathrm{D}_{6}$ & $1.2 \times 10^{5}$ & $1.6 \times 10^{3}$ & $1.4 \times 10^{2}$ \\
\hline & $\mathrm{D}_{7}$ & $2.0 \times 10^{5}$ & $1.1 \times 10^{3}$ & $1.3 \times 10^{2}$ \\
\hline & $D_{8}$ & $1.6 \times 10^{5}$ & $1.6 \times 10^{3}$ & $2.2 \times 10^{2}$ \\
\hline & $\mathrm{D}_{9}$ & $1.5 \times 10^{5}$ & $1.6 \times 10^{3}$ & $1.8 \times 10^{2}$ \\
\hline & $\mathrm{D}_{10}$ & $1.1 \times 10^{5}$ & $1.2 \times 10^{3}$ & $1.1 \times 10^{2}$ \\
\hline & Mean of means & $1.88 \times 10^{5 \mathrm{a}}$ & $1.54 \times 10^{3 \mathrm{~b}}$ & $1.72 \times 10^{2 \mathrm{c}}$ \\
\hline \multirow[t]{11}{*}{ Control } & Cont.1 & $1.1 \times 10^{4}$ & 0 & $1.1 \times 10$ \\
\hline & Cont. 2 & $1.5 \times 10^{4}$ & $1.0 \times 10^{2}$ & $1.0 \times 10$ \\
\hline & Cont. 3 & $1.2 \times 10^{4}$ & 0 & $2.0 \times 10$ \\
\hline & Cont.4 & $1.6 \times 10^{4}$ & $1.1 \times 10^{2}$ & $1.3 \times 10$ \\
\hline & Cont.5 & $1.0 \times 10^{4}$ & 0 & $1.2 \times 10$ \\
\hline & Cont.6 & $1.3 \times 10^{4}$ & 0 & $1.7 \times 10$ \\
\hline & Cont.7 & $1.4 \times 10^{4}$ & $1.0 \times 10^{2}$ & $2.1 \times 10$ \\
\hline & Cont. 8 & $1.2 \times 10^{4}$ & 0 & $1.0 \times 10$ \\
\hline & Cont.9 & $1.3 \times 10^{4}$ & 0 & $1.1 \times 10$ \\
\hline & Cont.10 & $1.4 \times 10^{4}$ & $1.6 \times 10^{2}$ & $1.5 \times 10$ \\
\hline & Mean & $1.30 \times 10^{4 \mathrm{~b}}$ & $0.47 \times 10^{2 \mathrm{c}}$ & $1.40 \times 10^{\mathrm{a}}$ \\
\hline
\end{tabular}

Each value $(1-10)$ in each zone represents mean of data obtained from six different suya spots in the area. Means of means with same superscript along same column showed no statistical difference. 
Bello and Bello/Carpathian Journal of Food Science and Technology, Special Issue 2020, 12(5), 81-98

Table 3. Morphological and biochemical characteristics of bacteria isolated from suya samples in Nigeria

\begin{tabular}{|c|c|c|c|c|c|c|c|c|c|c|c|c|c|c|c|c|c|c|c|c|c|c|c|c|c|c|c|c|c|}
\hline 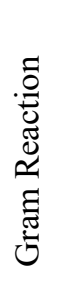 & 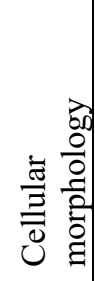 & $\frac{0}{\tilde{\Xi}}$ & 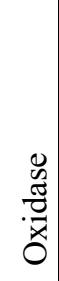 & 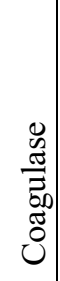 & $\begin{array}{l}\frac{0}{0} \\
\frac{O}{\Xi}\end{array}$ & 昜 & 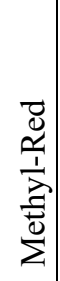 & 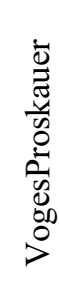 & 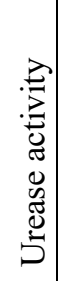 & 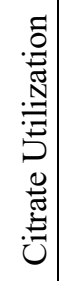 & 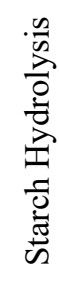 & $\begin{array}{l}\frac{n}{0} \\
2 \\
0 \\
0 \\
0 \\
0 \\
0 \\
0 \\
0 \\
0 \\
0\end{array}$ & 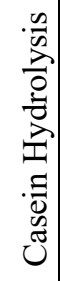 & 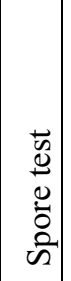 & 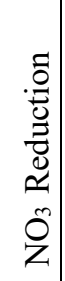 & $\begin{array}{c}0 \\
\infty \\
0 \\
0 \\
0 \\
0\end{array}$ & $\begin{array}{c}0 \\
\infty \\
0 \\
0 \\
0 \\
\tilde{D}\end{array}$ & 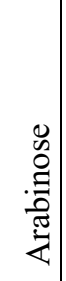 & $\begin{array}{l}0 \\
\mathscr{\infty} \\
\stackrel{0}{\Xi} \\
\stackrel{\pi}{\Sigma}\end{array}$ & 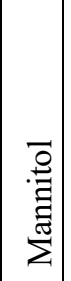 & $\begin{array}{l}0 \\
0 \\
\frac{0}{x} \\
x\end{array}$ & $\begin{array}{l}0 \\
0 \\
0 \\
0 \\
\frac{\pi}{\pi} \\
\tilde{J} \\
0\end{array}$ & $\begin{array}{l}\overline{0} \\
.0 \\
\dot{0} 0 \\
0 \\
\text { क }\end{array}$ & $\begin{array}{l}\overrightarrow{0} \\
.00 \\
0 \\
0 \\
0\end{array}$ & 点 & 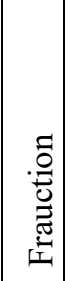 & 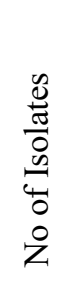 & Isolates per zone & $\begin{array}{l}\text { Most } \\
\text { Probable } \\
\text { Identity }\end{array}$ \\
\hline -ve & $\mathrm{R}$ & - & + & - & - & + & + & + & - & + & - & - & + & + & + & + & + & + & - & + & + & - & - & - & - & + & $\begin{array}{l}10 \\
5\end{array}$ & $\mathrm{~A}=25, \mathrm{~B}=25, \mathrm{C}=22, \mathrm{D}=22, \mathrm{CT}=11$ & E. coli \\
\hline -ve & $\mathrm{R}$ & + & - & - & - & + & - & + & - & + & + & - & - & - & + & + & + & + & + & + & + & + & + & + & ND & + & 55 & $\mathrm{~A}=11, \mathrm{~B}=11, \mathrm{C}=13, \mathrm{D}=13, \mathrm{CT}=7$ & $\begin{array}{l}\text { E. } \\
\text { aerogenes }\end{array}$ \\
\hline -ve & $\mathrm{R}$ & + & + & - & - & + & - & + & - & + & + & + & - & - & - & + & + & + & + & + & - & - & - & - & + & + & 85 & $\mathrm{~A}=19, \mathrm{~B}=20, \mathrm{C}=18, \mathrm{D}=17, \mathrm{CT}=11$ & S. rubidaea \\
\hline -ve & $\mathrm{R}$ & + & + & - & - & + & - & + & - & + & - & + & - & - & + & + & + & + & + & + & + & + & - & - & + & + & $\begin{array}{l}13 \\
7 \\
\end{array}$ & $\mathrm{~A}=30, \mathrm{~B}=28, \mathrm{C}=32, \mathrm{D}=32, \mathrm{CT}=15$ & $\begin{array}{l}P . \\
\text { aeruginosa }\end{array}$ \\
\hline+ ve & $\mathrm{C}$ & + & - & + & - & - & - & + & + & - & - & + & + & - & + & + & + & - & + & + & - & + & ND & ND & ND & + & $\begin{array}{l}11 \\
4\end{array}$ & $\mathrm{~A}=24, \mathrm{~B}=25, \mathrm{C}=24, \mathrm{D}=25, \mathrm{CT}=16$ & S. aureus \\
\hline+ ve & $\mathrm{R}$ & + & + & - & + & + & + & - & - & + & - & - & - & - & - & + & + & - & + & + & - & - & + & - & + & + & 54 & $\mathrm{~A}=12, \mathrm{~B}=11, \mathrm{C}=11, \mathrm{D}=12, \mathrm{CT}=8$ & C. freundii \\
\hline$+\mathrm{ve}$ & $\mathrm{C}$ & + & - & - & - & - & - & + & + & - & - & + & - & - & - & + & + & - & - & - & - & - & ND & ND & ND & + & $\begin{array}{l}12 \\
5\end{array}$ & $\mathrm{~A}=20, \mathrm{~B}=25, \mathrm{C}=30, \mathrm{D}=31, \mathrm{CT}=19$ & $\begin{array}{l}\text { S. } \\
\text { epidermidis }\end{array}$ \\
\hline+ ve & $\mathrm{R}$ & + & + & - & - & + & - & + & - & + & - & + & - & + & - & + & + & - & - & + & - & - & - & - & + & + & $\begin{array}{l}10 \\
7\end{array}$ & $\mathrm{~A}=24, \mathrm{~B}=24, \mathrm{C}=25, \mathrm{D}=22, \mathrm{CT}=12$ & B. cereus \\
\hline+ ve & $\mathrm{C}$ & + & - & - & - & - & - & - & + & - & - & + & - & - & - & + & + & - & + & + & - & - & - & - & ND & - & 85 & $\mathrm{~A}=20, \mathrm{~B}=18, \mathrm{C}=18, \mathrm{D}=18, \mathrm{CT}=11$ & M. luteus \\
\hline$+\mathrm{ve}$ & $\mathrm{R}$ & + & + & - & - & + & - & + & + & + & - & + & - & + & - & + & + & - & - & + & - & - & - & - & - & + & 26 & $\mathrm{~A}=7, \mathrm{~B}=6, \mathrm{C}=5, \mathrm{D}=5, \mathrm{CT}=3$ & B. subtilis \\
\hline$+\mathrm{ve}$ & $\mathrm{R}$ & - & - & - & - & + & - & - & - & - & + & - & + & + & + & + & + & + & + & + & + & - & - & - & + & + & 27 & $\mathrm{~A}=8, \mathrm{~B}=17, \mathrm{C}=0, \mathrm{D}=2, \mathrm{CT}=0$ & $\begin{array}{l}C . \\
\text { butyricum } \\
\end{array}$ \\
\hline -ve & $\mathrm{R}$ & + & - & - & - & - & - & + & + & + & + & + & + & - & + & + & + & + & + & + & + & - & - & + & - & + & 47 & $\mathrm{~A}=11, \mathrm{~B}=7, \mathrm{C}=12, \mathrm{D}=13, \mathrm{CT}=4$ & $\begin{array}{l}K . \\
\text { pneumoniae }\end{array}$ \\
\hline -ve & $\mathrm{R}$ & - & - & - & - & - & + & + & + & + & + & - & - & - & - & + & + & + & + & + & - & + & - & + & - & - & 32 & $\mathrm{~A}=6, \mathrm{~B}=6, \mathrm{C}=7, \mathrm{D}=7, \mathrm{CT}=6$ & $\begin{array}{l}\text { K. } \\
\text { planticola }\end{array}$ \\
\hline -ve & $\mathrm{R}$ & + & & - & - & + & - & + & - & + & + & - & - & - & + & + & - & - & + & + & - & - & - & - & - & + & 15 & $\mathrm{~A}=4, \mathrm{~B}=3, \mathrm{C}=3, \mathrm{D}=5, \mathrm{CT}=0$ & $\begin{array}{l}S . \\
\text { enterica Typ } \\
\text { himurium }\end{array}$ \\
\hline
\end{tabular}

Keys: $\mathrm{R}=$ Rods; + = Positive reaction; - = Negative reaction; $\mathrm{ND}=$ Not determined; $\mathrm{A}=$ Zone $\mathrm{A} ; \mathrm{B}=\mathrm{Zone} \mathrm{B}$; $\mathrm{C}=\mathrm{Zone} \mathrm{C}$; $\mathrm{D}=\mathrm{Z}$ one $\mathrm{D}$ and $\mathrm{CT}$

$=$ Control. 
Bello and Bello/Carpathian Journal of Food Science and Technology, Special Issue 2020, 12(5), 81-98

Table 4. Percentage antibiotic susceptibility of bacterial isolates from suya meat samples in Nigeria

\begin{tabular}{|c|c|c|c|c|c|c|c|c|c|c|c|c|c|c|c|}
\hline Antibiotic & & $\begin{array}{l}\ddot{\tilde{0}} \\
0 \\
\dot{1}\end{array}$ & 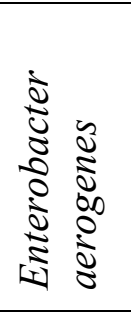 & 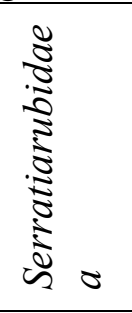 & $\begin{array}{c}0 \\
0 \\
0 \\
0 \\
0 \\
0 \\
0 \\
0 \\
0 \\
0 \\
0\end{array}$ & 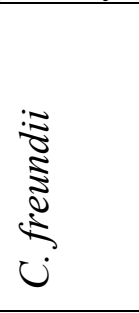 & $\begin{array}{c}y \\
\vdots \\
0 \\
\vdots \\
\vdots \\
\dot{5} \\
\dot{y}\end{array}$ & 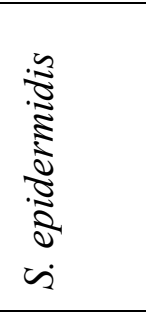 & 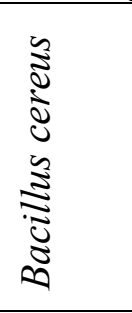 & 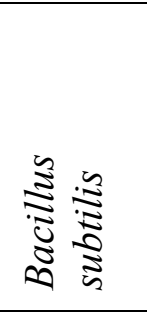 & 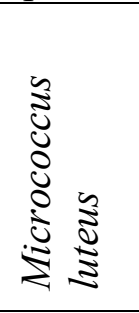 & 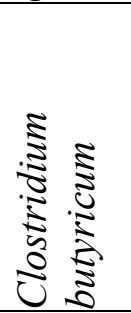 & 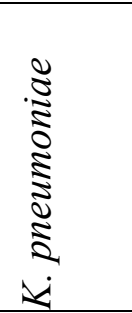 & $\begin{array}{l}\frac{0}{0} \\
0 \\
0 \\
\vdots \\
0 \\
0 \\
-1 \\
ن\end{array}$ & 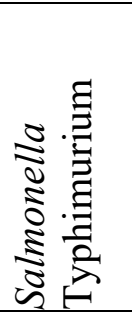 \\
\hline & Status & $\mathrm{n}=105$ & $\mathrm{n}=55$ & $\mathrm{n}=85$ & $\mathrm{n}=137$ & $\mathrm{n}=54$ & $\mathrm{n}=114$ & $\mathrm{n}=125$ & $\mathrm{n}=107$ & $n=26$ & $\mathrm{n}=85$ & $n=27$ & $\mathrm{n}=47$ & $\mathrm{n}=32$ & $\mathrm{n}=15$ \\
\hline \multirow[t]{3}{*}{ Tetracycline } & $\mathrm{S}$ & $\begin{array}{c}105 \\
(100 \%)\end{array}$ & $\begin{array}{c}55 \\
(100 \%)\end{array}$ & $\begin{array}{c}80 \\
(94.1 \%)\end{array}$ & $\begin{array}{c}5 \\
(3.7 \%)\end{array}$ & $\begin{array}{c}54 \\
(100 \%)\end{array}$ & $\begin{array}{c}80 \\
(70.2 \%)\end{array}$ & $\begin{array}{c}125 \\
(100 \%)\end{array}$ & $\begin{array}{c}76 \\
(71 \%)\end{array}$ & $\begin{array}{c}26 \\
(100 \%)\end{array}$ & $\begin{array}{c}85 \\
(100 \%)\end{array}$ & $\begin{array}{c}20 \\
(74.1 \%)\end{array}$ & $\begin{array}{c}29 \\
(61.7 \%)\end{array}$ & $\begin{array}{c}32 \\
(100 \%)\end{array}$ & $\begin{array}{c}15 \\
(100 \%)\end{array}$ \\
\hline & I & 0 & 0 & $\begin{array}{c}5 \\
(5.9 \%)\end{array}$ & 0 & 0 & $\begin{array}{c}4 \\
(3.5 \%)\end{array}$ & 0 & 0 & 0 & 0 & 0 & $\begin{array}{c}4 \\
(8.5 \%)\end{array}$ & 0 & 0 \\
\hline & $\mathrm{R}$ & 0 & 0 & 0 & $\begin{array}{c}132 \\
(96.4 \%)\end{array}$ & 0 & $\begin{array}{c}30 \\
(26.3 \%)\end{array}$ & 0 & $\begin{array}{c}31 \\
(29 \%)\end{array}$ & 0 & 0 & $\begin{array}{c}7 \\
(25.9 \%)\end{array}$ & $\begin{array}{c}14 \\
(51.9 \%) \\
\end{array}$ & 0 & 0 \\
\hline \multirow[t]{3}{*}{ Doxycycline } & $\mathrm{S}$ & $\begin{array}{c}105 \\
(100 \%)\end{array}$ & $\begin{array}{c}55 \\
(100 \%) \\
\end{array}$ & $\begin{array}{c}85 \\
(100 \%) \\
\end{array}$ & $\begin{array}{c}38 \\
(27.7 \%) \\
\end{array}$ & $\begin{array}{c}54 \\
(100 \%) \\
\end{array}$ & $\begin{array}{c}99 \\
(86.8 \%) \\
\end{array}$ & $\begin{array}{c}125 \\
(100 \%) \\
\end{array}$ & $\begin{array}{c}107 \\
(100 \%)\end{array}$ & $\begin{array}{c}26 \\
(100 \%) \\
\end{array}$ & $\begin{array}{c}79 \\
(92.9 \%) \\
\end{array}$ & $\begin{array}{c}27 \\
(100 \%)\end{array}$ & $\begin{array}{c}47 \\
(100 \%)\end{array}$ & $\begin{array}{c}32 \\
(100 \%)\end{array}$ & $\begin{array}{c}15 \\
(100 \%)\end{array}$ \\
\hline & $\mathrm{I}$ & 0 & 0 & 0 & 0 & 0 & 0 & 0 & 0 & 0 & $\begin{array}{c}6 \\
(7.1 \%) \\
\end{array}$ & 0 & 0 & 0 & 0 \\
\hline & $\mathrm{R}$ & 0 & 0 & 0 & $\begin{array}{c}99 \\
(72.3 \%)\end{array}$ & 0 & $\begin{array}{c}15 \\
(13.1 \%)\end{array}$ & 0 & 0 & 0 & 0 & 0 & 0 & 0 & 0 \\
\hline \multirow{2}{*}{ Minocycline } & $\mathrm{I}$ & 0 & 0 & 0 & 0 & 0 & 0 & 0 & 0 & 0 & 0 & 0 & 0 & 0 & 0 \\
\hline & $\mathrm{R}$ & 0 & 0 & $\begin{array}{c}21 \\
(24.7 \%) \\
\end{array}$ & $\begin{array}{c}82 \\
(59.9 \%) \\
\end{array}$ & 0 & $\begin{array}{c}11 \\
(9.7 \%) \\
\end{array}$ & 0 & 0 & 0 & 0 & 0 & 0 & 0 & 0 \\
\hline \multirow[t]{3}{*}{ Erythromycin } & $\mathrm{S}$ & $\begin{array}{c}77 \\
(73.3 \%) \\
\end{array}$ & $\begin{array}{c}34 \\
(61.8 \%) \\
\end{array}$ & $\begin{array}{c}25 \\
(29.4 \%) \\
\end{array}$ & 0 & $\begin{array}{c}29 \\
(53.7 \%) \\
\end{array}$ & $\begin{array}{c}114 \\
(100 \%) \\
\end{array}$ & $\begin{array}{c}107 \\
(85.6 \%) \\
\end{array}$ & $\begin{array}{c}38 \\
(35.5 \%) \\
\end{array}$ & $\begin{array}{c}11 \\
(42.3 \%) \\
\end{array}$ & $\begin{array}{c}71 \\
(83.5 \%) \\
\end{array}$ & $\begin{array}{c}20 \\
(74.1 \%) \\
\end{array}$ & $\begin{array}{c}15 \\
(31.9 \%) \\
\end{array}$ & $\begin{array}{c}12 \\
(37.5 \%) \\
\end{array}$ & $\begin{array}{c}4 \\
(26.7 \%) \\
\end{array}$ \\
\hline & I & $\begin{array}{c}5 \\
(1.0 \%) \\
\end{array}$ & 0 & 0 & $\begin{array}{c}10 \\
(7.3 \%)\end{array}$ & 0 & 0 & 0 & 0 & 0 & 0 & 0 & $\begin{array}{c}6 \\
(12.8 \%) \\
\end{array}$ & 0 & $\begin{array}{c}2 \\
(13.3 \%) \\
\end{array}$ \\
\hline & $\mathrm{R}$ & $\begin{array}{c}23 \\
(21.9 \%) \\
\end{array}$ & $\begin{array}{c}21 \\
(38.2 \%)\end{array}$ & $\begin{array}{c}20 \\
(23.5 \%) \\
\end{array}$ & $\begin{array}{c}127 \\
(92.7 \%)\end{array}$ & $\begin{array}{c}26 \\
(48.2 \%)\end{array}$ & 0 & $\begin{array}{c}18 \\
(14.4 \%) \\
\end{array}$ & $\begin{array}{c}69 \\
(64.5 \%) \\
\end{array}$ & $\begin{array}{c}15 \\
(57.7 \%) \\
\end{array}$ & $\begin{array}{c}14 \\
(16.5 \%)\end{array}$ & $\begin{array}{c}7 \\
(25.9 \%)\end{array}$ & $\begin{array}{c}26 \\
(55.3 \%) \\
\end{array}$ & $\begin{array}{c}20 \\
(62.5 \%)\end{array}$ & $\begin{array}{c}9 \\
(60 \%)\end{array}$ \\
\hline
\end{tabular}

Keys: $\mathrm{S}=$ Suseptible; $\mathrm{I}=$ Intermediately Susceptible and $\mathrm{R}=$ Resistance 
Bello and Bello/Carpathian Journal of Food Science and Technology, Special Issue 2020, 12(5), 81-98

\begin{tabular}{|c|c|c|c|c|c|c|c|c|c|c|c|c|c|c|c|}
\hline Antibiotic & & $\begin{array}{l}\ddot{8} \\
0 \\
\dot{0}\end{array}$ & 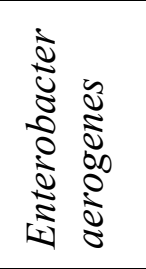 & 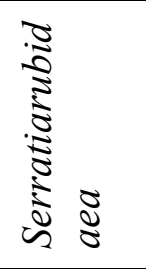 & 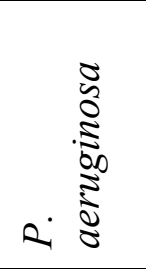 & 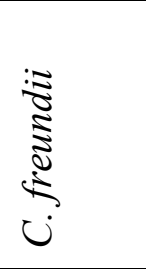 & 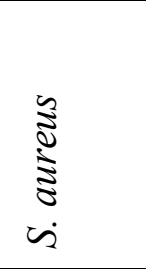 & 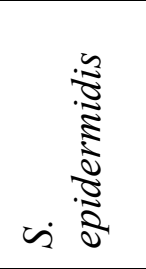 & 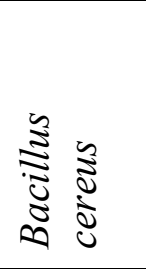 & 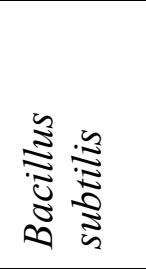 & 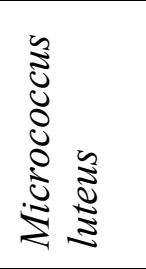 & 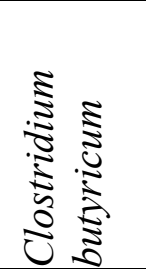 & 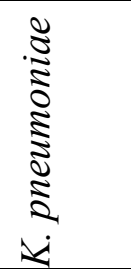 & 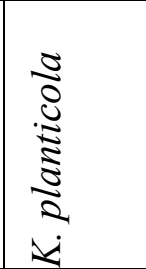 & 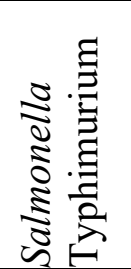 \\
\hline & Status & $\mathrm{n}=105$ & $\mathrm{n}=55$ & $\mathrm{n}=85$ & $\mathrm{n}=137$ & $\mathrm{n}=54$ & $\mathrm{n}=114$ & $\mathrm{n}=125$ & $\mathrm{n}=107$ & $n=26$ & $\mathrm{n}=85$ & $\mathrm{n}=27$ & $\mathrm{n}=47$ & $\mathrm{n}=32$ & $\mathrm{n}=15$ \\
\hline \multirow[t]{3}{*}{ Colistin } & $\mathrm{S}$ & $\begin{array}{c}105 \\
(100 \%)\end{array}$ & $\begin{array}{c}55 \\
(100 \%)\end{array}$ & $\begin{array}{c}85 \\
(100 \%)\end{array}$ & $\begin{array}{c}137 \\
(100 \%)\end{array}$ & $\begin{array}{c}54 \\
(100 \%)\end{array}$ & $\begin{array}{c}11 \\
(9.7 \%)\end{array}$ & $\begin{array}{c}13 \\
(10.4 \%)\end{array}$ & 0 & 0 & $\begin{array}{c}14 \\
(16.5 \%)\end{array}$ & 0 & $\begin{array}{c}47 \\
(100 \%)\end{array}$ & $\begin{array}{c}32 \\
(100 \%)\end{array}$ & $\begin{array}{c}15 \\
(100 \%)\end{array}$ \\
\hline & I & 0 & 0 & 0 & 0 & 0 & $\begin{array}{c}14 \\
(12.3 \%) \\
\end{array}$ & 0 & $\begin{array}{c}11 \\
(10.3 \%) \\
\end{array}$ & 0 & 0 & 0 & 0 & 0 & 0 \\
\hline & $\mathrm{R}$ & 0 & 0 & 0 & 0 & 0 & $\begin{array}{c}89 \\
(78.1 \%)\end{array}$ & $\begin{array}{c}112 \\
(89.6 \%)\end{array}$ & $\begin{array}{c}96 \\
(89.7 \%)\end{array}$ & $\begin{array}{c}26 \\
(100 \%)\end{array}$ & $\begin{array}{c}71 \\
(83.5 \%)\end{array}$ & $\begin{array}{c}27 \\
(100 \%)\end{array}$ & 0 & 0 & 0 \\
\hline \multirow{3}{*}{$\begin{array}{l}\text { Chlorampheni- } \\
\text { col }\end{array}$} & $\mathrm{S}$ & $\begin{array}{c}105 \\
(100 \%)\end{array}$ & $\begin{array}{c}49 \\
(89.1 \%) \\
\end{array}$ & $\begin{array}{c}85 \\
(100 \%) \\
\end{array}$ & $\begin{array}{c}38 \\
(27.7 \%) \\
\end{array}$ & $\begin{array}{c}54 \\
(100 \%)\end{array}$ & $\begin{array}{c}107 \\
(93.9 \%) \\
\end{array}$ & $\begin{array}{c}91 \\
(72.8 \%) \\
\end{array}$ & $\begin{array}{c}84 \\
(78.5 \%) \\
\end{array}$ & $\begin{array}{c}12 \\
(24.3 \%)\end{array}$ & $\begin{array}{c}79 \\
(92.9 \%) \\
\end{array}$ & $\begin{array}{c}16 \\
(59.3 \%)\end{array}$ & $\begin{array}{c}47 \\
(100 \%)\end{array}$ & $\begin{array}{c}32 \\
(100 \%)\end{array}$ & $\begin{array}{c}11 \\
(73.3 \%)\end{array}$ \\
\hline & I & 0 & $\begin{array}{c}6 \\
(10.9 \%)\end{array}$ & 0 & $\begin{array}{c}19 \\
(13.9 \%) \\
\end{array}$ & 0 & 0 & 0 & 0 & 0 & 0 & $\begin{array}{c}5 \\
(18.5 \%) \\
\end{array}$ & 0 & 0 & 0 \\
\hline & $\mathrm{R}$ & 0 & 0 & 0 & $\begin{array}{c}80 \\
(58.4 \%) \\
\end{array}$ & 0 & $\begin{array}{c}7 \\
(6.1 \%) \\
\end{array}$ & $\begin{array}{c}34 \\
(27.2 \%) \\
\end{array}$ & $\begin{array}{c}23 \\
(21.5 \%) \\
\end{array}$ & $\begin{array}{c}14 \\
(13.1 \%) \\
\end{array}$ & $\begin{array}{c}6 \\
(7.1 \%) \\
\end{array}$ & $\begin{array}{c}6 \\
(22.2 \%) \\
\end{array}$ & 0 & 0 & $\begin{array}{c}4 \\
(26.7 \%) \\
\end{array}$ \\
\hline \multirow{3}{*}{$\begin{array}{l}\text { Trimethoprim/ } \\
\text { sulfamethoxaz- } \\
\text { ole }\end{array}$} & $\mathrm{S}$ & $\begin{array}{c}105 \\
(100 \%)\end{array}$ & $\begin{array}{c}55 \\
(100 \%)\end{array}$ & $\begin{array}{c}85 \\
(100 \%)\end{array}$ & $\begin{array}{c}58 \\
(42.3 \%)\end{array}$ & $\begin{array}{c}54 \\
(100 \%)\end{array}$ & $\begin{array}{c}109 \\
(95.6 \%)\end{array}$ & $\begin{array}{c}125 \\
(100 \%)\end{array}$ & $\begin{array}{c}107 \\
(100 \%)\end{array}$ & $\begin{array}{c}26 \\
(100 \%)\end{array}$ & $\begin{array}{c}78 \\
(91.8 \%)\end{array}$ & $\begin{array}{c}9 \\
(33.3 \%)\end{array}$ & $\begin{array}{c}47 \\
(100 \%)\end{array}$ & $\begin{array}{c}32 \\
(100 \%)\end{array}$ & $\begin{array}{c}15 \\
(100 \%)\end{array}$ \\
\hline & I & 0 & 0 & 0 & 0 & 0 & $\begin{array}{c}5 \\
(4.4 \%) \\
\end{array}$ & 0 & 0 & 0 & 0 & $\begin{array}{c}4 \\
(14.8 \%) \\
\end{array}$ & 0 & 0 & 0 \\
\hline & $\mathrm{R}$ & 0 & 0 & 0 & $\begin{array}{c}79 \\
(57.7 \%) \\
\end{array}$ & 0 & 0 & 0 & 0 & 0 & $\begin{array}{c}7 \\
(8.2 \%) \\
\end{array}$ & $\begin{array}{c}14 \\
(51.9 \%) \\
\end{array}$ & 0 & 0 & 0 \\
\hline \multirow[t]{3}{*}{ Gentamicin } & $\mathrm{S}$ & $\begin{array}{c}87 \\
(82.9 \%) \\
\end{array}$ & $\begin{array}{c}55 \\
(100 \%)\end{array}$ & $\begin{array}{c}85 \\
(100 \%)\end{array}$ & $\begin{array}{c}73 \\
(53.3 \%)\end{array}$ & $\begin{array}{c}54 \\
(100 \%)\end{array}$ & $\begin{array}{c}80 \\
(70.2 \%)\end{array}$ & $\begin{array}{c}106 \\
(84.8 \%)\end{array}$ & $\begin{array}{c}81 \\
(75.7 \%)\end{array}$ & $\begin{array}{c}18 \\
(69.2 \%)\end{array}$ & $\begin{array}{c}85 \\
(100 \%)\end{array}$ & $\begin{array}{c}10 \\
(3.7 \%)\end{array}$ & $\begin{array}{c}39 \\
(83 \%)\end{array}$ & $\begin{array}{c}32 \\
(100 \%)\end{array}$ & $\begin{array}{c}15 \\
(100 \%)\end{array}$ \\
\hline & I & 0 & 0 & 0 & 0 & 0 & $\begin{array}{c}9 \\
(7.9 \%)\end{array}$ & $\begin{array}{c}7 \\
(5.6 \%)\end{array}$ & 0 & 0 & 0 & $\begin{array}{c}5 \\
(18.5 \%)\end{array}$ & 0 & 0 & 0 \\
\hline & $\mathrm{R}$ & $\begin{array}{c}18 \\
(17.1 \%)\end{array}$ & 0 & 0 & $\begin{array}{c}64 \\
(46.7 \%)\end{array}$ & 0 & $\begin{array}{c}25 \\
(21.9 \%)\end{array}$ & $\begin{array}{c}12 \\
(9.6 \%)\end{array}$ & $\begin{array}{c}26 \\
(24.3 \%)\end{array}$ & $\begin{array}{c}18 \\
(69.2 \%)\end{array}$ & 0 & $\begin{array}{c}12 \\
(44.4 \%)\end{array}$ & $\begin{array}{c}8 \\
(17 \%)\end{array}$ & 0 & 0 \\
\hline
\end{tabular}


Bello and Bello/Carpathian Journal of Food Science and Technology, Special Issue 2020, 12(5), 81-98

\begin{tabular}{|c|c|c|c|c|c|c|c|c|c|c|c|c|c|c|c|}
\hline Antibiotic & & $\begin{array}{l}\overrightarrow{0} \\
0 \\
ن\end{array}$ & 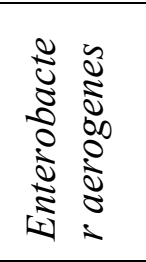 & 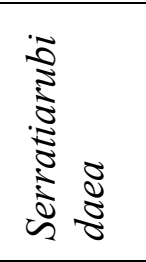 & 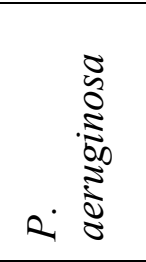 & 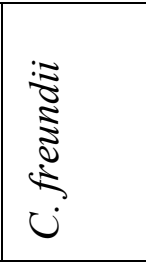 & 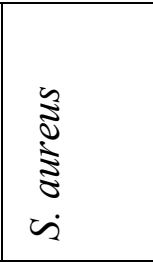 & 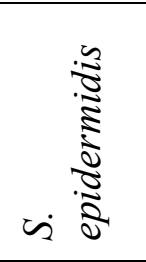 & 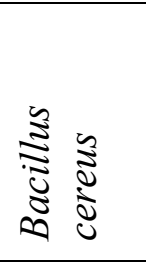 & 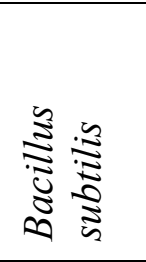 & 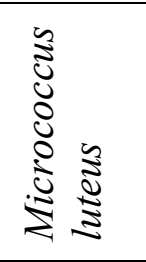 & 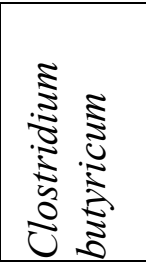 & 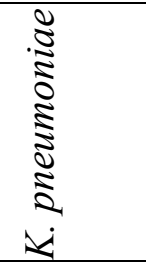 & 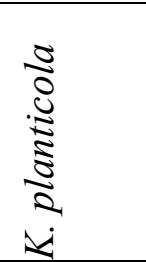 & 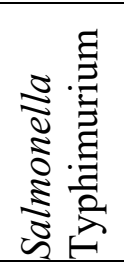 \\
\hline & Status & $\mathrm{n}=105$ & $\mathrm{n}=55$ & $\mathrm{n}=85$ & $n=137$ & $\mathrm{n}=54$ & $\mathrm{n}=114$ & $\mathrm{n}=125$ & $\mathrm{n}=107$ & $\mathrm{n}=26$ & $\mathrm{n}=85$ & $\mathrm{n}=27$ & $\mathrm{n}=47$ & $\mathrm{n}=32$ & $\mathrm{n}=15$ \\
\hline \multirow[t]{3}{*}{ Rifampicin } & $\mathrm{S}$ & 0 & 0 & $\begin{array}{c}29 \\
(34.1 \%)\end{array}$ & 0 & $\begin{array}{c}29 \\
(53.7 \%)\end{array}$ & $\begin{array}{c}114 \\
(100 \%)\end{array}$ & $\begin{array}{c}125 \\
(100 \%)\end{array}$ & $\begin{array}{c}39 \\
(36.5 \%)\end{array}$ & $\begin{array}{c}9 \\
(34.6 \%)\end{array}$ & $\begin{array}{c}85 \\
(100 \%)\end{array}$ & 0 & 0 & 0 & 0 \\
\hline & I & 0 & 0 & $\begin{array}{c}9 \\
(10.6 \%) \\
\end{array}$ & 0 & $\begin{array}{c}5 \\
(9.3 \%) \\
\end{array}$ & 0 & 0 & $\begin{array}{c}14 \\
(13.1 \%) \\
\end{array}$ & 0 & 0 & 0 & 0 & 0 & 0 \\
\hline & $\mathrm{R}$ & $\begin{array}{c}105 \\
(100 \%)\end{array}$ & $\begin{array}{c}55 \\
(100 \%)\end{array}$ & $\begin{array}{c}47 \\
(55.3 \%)\end{array}$ & $\begin{array}{c}137 \\
(100 \%)\end{array}$ & $\begin{array}{c}20 \\
(37 \%)\end{array}$ & 0 & 0 & $\begin{array}{c}54 \\
(50.5 \%)\end{array}$ & $\begin{array}{c}17 \\
(64.5 \%)\end{array}$ & 0 & $\begin{array}{c}27 \\
(100 \%)\end{array}$ & $\begin{array}{c}47 \\
(100 \%)\end{array}$ & $\begin{array}{c}32 \\
(100 \%)\end{array}$ & $\begin{array}{c}15 \\
(100 \%)\end{array}$ \\
\hline \multirow[t]{3}{*}{ Nalidixic acid } & $\mathrm{S}$ & $\begin{array}{c}76 \\
(72.4 \%) \\
\end{array}$ & $\begin{array}{c}48 \\
(87.3 \%) \\
\end{array}$ & $\begin{array}{c}64 \\
(75.3 \%) \\
\end{array}$ & 0 & $\begin{array}{c}31 \\
(57.4 \%) \\
\end{array}$ & 0 & 0 & 0 & 0 & 0 & \begin{tabular}{|c|}
27 \\
$(100 \%)$ \\
\end{tabular} & $\begin{array}{c}36 \\
(76.6 \%) \\
\end{array}$ & $\begin{array}{c}32 \\
(100 \%) \\
\end{array}$ & $\begin{array}{c}12 \\
(80 \%) \\
\end{array}$ \\
\hline & I & $\begin{array}{c}8 \\
(7.6 \%) \\
\end{array}$ & 0 & 0 & $\begin{array}{c}5 \\
(3.7 \%) \\
\end{array}$ & 0 & 0 & 0 & $\begin{array}{c}8 \\
(7.48 \%)\end{array}$ & 0 & 0 & 0 & 0 & 0 & 0 \\
\hline & $\mathrm{R}$ & $\begin{array}{c}21 \\
(20 \%)\end{array}$ & $\begin{array}{c}7 \\
(12.7 \%)\end{array}$ & $\begin{array}{c}21 \\
(24.7 \%)\end{array}$ & $\begin{array}{c}132 \\
(96.4 \%)\end{array}$ & $\begin{array}{c}23 \\
(42.6 \%)\end{array}$ & $\begin{array}{c}114 \\
(100 \%)\end{array}$ & $\begin{array}{c}125 \\
(100 \%)\end{array}$ & $\begin{array}{c}99 \\
(92.5 \%)\end{array}$ & $\begin{array}{c}26 \\
(100 \%)\end{array}$ & $\begin{array}{c}85 \\
(100 \%)\end{array}$ & 0 & $\begin{array}{c}11 \\
(23.4 \%)\end{array}$ & 0 & $\begin{array}{c}3 \\
(20 \%)\end{array}$ \\
\hline \multirow[t]{2}{*}{ Ciprofloxacin } & $\mathrm{S}$ & $\begin{array}{c}83 \\
(79.1 \%) \\
\end{array}$ & $\begin{array}{c}55 \\
(100 \%) \\
\end{array}$ & $\begin{array}{c}85 \\
(100 \%) \\
\end{array}$ & $\begin{array}{c}68 \\
(49.6 \%) \\
\end{array}$ & $\begin{array}{c}54 \\
(100 \%) \\
\end{array}$ & $\begin{array}{c}99 \\
(86.8 \%) \\
\end{array}$ & $\begin{array}{c}106 \\
(84.8 \%) \\
\end{array}$ & $\begin{array}{c}27 \\
(25.2 \%) \\
\end{array}$ & $\begin{array}{c}20 \\
(76.9 \%) \\
\end{array}$ & $\begin{array}{c}31 \\
(36.5 \%) \\
\end{array}$ & 10 & $\begin{array}{c}41 \\
(87.2 \%) \\
\end{array}$ & $\begin{array}{c}32 \\
(100 \%) \\
\end{array}$ & $\begin{array}{c}15 \\
(100 \%) \\
\end{array}$ \\
\hline & $\mathrm{R}$ & $\begin{array}{c}22 \\
(21 \%)\end{array}$ & 0 & 0 & $\begin{array}{c}69 \\
(50.4 \%)\end{array}$ & 0 & $\begin{array}{c}11 \\
(9.7 \%)\end{array}$ & $\begin{array}{c}12 \\
(9.6 \%)\end{array}$ & $\begin{array}{c}80 \\
(74.8 \%)\end{array}$ & $\begin{array}{c}6 \\
(23.1 \%)\end{array}$ & $\begin{array}{c}54 \\
(63.5 \%)\end{array}$ & 12 & $\begin{array}{c}6 \\
(12.8 \%)\end{array}$ & 0 & 0 \\
\hline \multirow[t]{3}{*}{ Penicillin G } & $\mathrm{S}$ & 0 & 0 & $\begin{array}{c}34 \\
(40 \%) \\
\end{array}$ & 0 & $\begin{array}{c}37 \\
(68.5 \%) \\
\end{array}$ & $\begin{array}{c}92 \\
(80.7 \%) \\
\end{array}$ & $\begin{array}{c}102 \\
(81.6 \%) \\
\end{array}$ & $\begin{array}{c}77 \\
(72 \%) \\
\end{array}$ & $\begin{array}{c}22 \\
(84.6 \%) \\
\end{array}$ & $\begin{array}{c}85 \\
(100 \%) \\
\end{array}$ & $\begin{array}{c}27 \\
(100 \%) \\
\end{array}$ & 0 & 0 & 0 \\
\hline & $\mathrm{I}$ & 0 & 0 & 0 & 0 & $\begin{array}{c}2 \\
(3.7 \%) \\
\end{array}$ & 0 & 0 & 0 & 0 & 0 & 0 & 0 & 0 & 0 \\
\hline & $\mathrm{R}$ & $\begin{array}{c}105 \\
(100 \%)\end{array}$ & $\begin{array}{c}55 \\
(100 \%)\end{array}$ & $\begin{array}{c}51 \\
(60 \%)\end{array}$ & $\begin{array}{c}137 \\
(100 \%)\end{array}$ & $\begin{array}{c}15 \\
(27.8 \%)\end{array}$ & $\begin{array}{c}22 \\
(19.3 \%)\end{array}$ & $\begin{array}{c}23 \\
(18.4 \%)\end{array}$ & $\begin{array}{c}30 \\
(28.7 \%)\end{array}$ & $\begin{array}{c}4 \\
(15.4 \%)\end{array}$ & 0 & 0 & $\begin{array}{c}47 \\
(100 \%)\end{array}$ & $\begin{array}{c}32 \\
(100 \%)\end{array}$ & $\begin{array}{c}15 \\
(100 \%)\end{array}$ \\
\hline
\end{tabular}


Bello and Bello/Carpathian Journal of Food Science and Technology, Special Issue 2020, 12(5), 81-98

\begin{tabular}{|c|c|c|c|c|c|c|c|c|c|c|c|c|c|c|c|}
\hline Antibiotic & Status & $\begin{array}{l}\dot{\tilde{0}} \\
\dot{0}\end{array}$ & 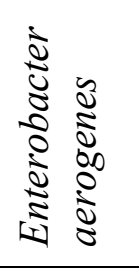 & 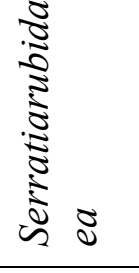 & $\begin{array}{c}0 \\
0 \\
0 \\
0 \\
0 \\
0 \\
0 \\
0 \\
0 \\
0 \\
0\end{array}$ & $\underbrace{i \tilde{\Xi}}_{i}$ & 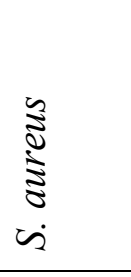 & 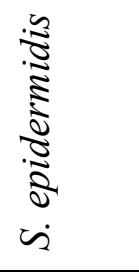 & 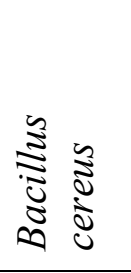 & 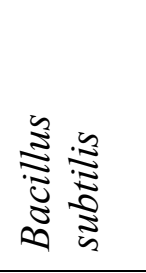 & 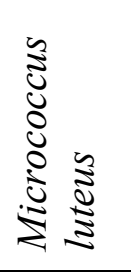 & 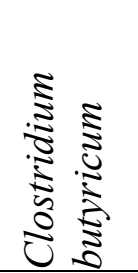 & 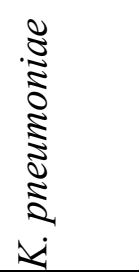 & $\begin{array}{l}\frac{0}{0} \\
0 \\
0 \\
0 \\
0 \\
0 \\
ن \\
ن\end{array}$ & 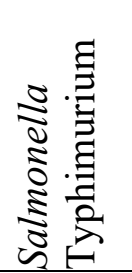 \\
\hline & & $\mathrm{n}=105$ & $\mathrm{n}=55$ & $\mathrm{n}=85$ & $\mathrm{n}=137$ & $\mathrm{n}=54$ & $\mathrm{n}=114$ & $\mathrm{n}=125$ & $\mathrm{n}=107$ & $n=26$ & $\mathrm{n}=85$ & $\mathrm{n}=27$ & $\mathrm{n}=47$ & $n=32$ & $n=15$ \\
\hline \multirow[t]{3}{*}{ Ampicillin } & $\mathrm{S}$ & $\begin{array}{c}71 \\
(67.7 \%)\end{array}$ & $\begin{array}{c}48 \\
(87.3 \%)\end{array}$ & $\begin{array}{c}64 \\
(75.3 \%)\end{array}$ & $\begin{array}{c}58 \\
(42.3 \%)\end{array}$ & $\begin{array}{c}50 \\
(92.6 \%)\end{array}$ & $\begin{array}{c}80 \\
(70.2 \%)\end{array}$ & $\begin{array}{c}97 \\
(77.6 \%)\end{array}$ & $\begin{array}{c}54 \\
(50.5 \%)\end{array}$ & $\begin{array}{c}19 \\
(73.1 \%)\end{array}$ & $\begin{array}{c}62 \\
(72.9 \%)\end{array}$ & $\begin{array}{c}9 \\
(33.3 \%)\end{array}$ & $\begin{array}{c}26 \\
(55.3 \%)\end{array}$ & $\begin{array}{c}23 \\
(71.9 \%)\end{array}$ & $\begin{array}{c}10 \\
(66.7 \%)\end{array}$ \\
\hline & I & 0 & 0 & 0 & $\begin{array}{c}7 \\
(5.1 \%) \\
\end{array}$ & 0 & $\begin{array}{c}4 \\
(3.5 \%) \\
\end{array}$ & $\begin{array}{c}8 \\
(6.4 \%) \\
\end{array}$ & $\begin{array}{c}8 \\
(7.5 \%) \\
\end{array}$ & 0 & $\begin{array}{c}7 \\
(8.2 \%) \\
\end{array}$ & 0 & 0 & 0 & 0 \\
\hline & $\mathrm{R}$ & $\begin{array}{c}34 \\
(32.4 \%) \\
\end{array}$ & $\begin{array}{c}7 \\
(12.7 \%) \\
\end{array}$ & $\begin{array}{c}21 \\
(24.7 \%) \\
\end{array}$ & $\begin{array}{c}72 \\
(52.6 \%) \\
\end{array}$ & $\begin{array}{c}4 \\
(7.4 \%) \\
\end{array}$ & $\begin{array}{c}30 \\
(26.3 \%) \\
\end{array}$ & $\begin{array}{c}20 \\
(16 \%) \\
\end{array}$ & $\begin{array}{c}45 \\
(42.1 \%) \\
\end{array}$ & $\begin{array}{c}7 \\
(26.9 \%) \\
\end{array}$ & $\begin{array}{c}16 \\
(18.8 \%) \\
\end{array}$ & $\begin{array}{c}18 \\
(66.7 \%) \\
\end{array}$ & $\begin{array}{c}21 \\
(44.7 \%) \\
\end{array}$ & $\begin{array}{c}9 \\
(28.1) \\
\end{array}$ & $\begin{array}{c}5 \\
(33.3 \%) \\
\end{array}$ \\
\hline \multirow[t]{3}{*}{ Imipenem } & $\mathrm{S}$ & $\begin{array}{c}101 \\
(100 \%)\end{array}$ & $\begin{array}{c}55 \\
(100 \%)\end{array}$ & $\begin{array}{c}85 \\
(100 \%)\end{array}$ & $\begin{array}{c}137 \\
(100 \%)\end{array}$ & $\begin{array}{c}54 \\
(100 \%) \\
\end{array}$ & $\begin{array}{c}100 \\
(87.7 \%)\end{array}$ & $\begin{array}{c}125 \\
(100 \%)\end{array}$ & $\begin{array}{c}89 \\
(83.2 \%)\end{array}$ & $\begin{array}{c}26 \\
(100 \%) \\
\end{array}$ & $\begin{array}{c}68 \\
(80 \%)\end{array}$ & $\begin{array}{c}27 \\
(100 \%)\end{array}$ & $\begin{array}{c}32 \\
(68.1 \%)\end{array}$ & $\begin{array}{c}32 \\
(100 \%) \\
\end{array}$ & $\begin{array}{c}11 \\
(73.3 \%)\end{array}$ \\
\hline & $\mathrm{I}$ & 0 & 0 & 0 & 0 & 0 & $\begin{array}{c}10 \\
(8.8 \%)\end{array}$ & 0 & $\begin{array}{c}6 \\
(5.6 \%) \\
\end{array}$ & 0 & 0 & 0 & 0 & 0 & 0 \\
\hline & $\mathrm{R}$ & 0 & 0 & 0 & 0 & 0 & $\begin{array}{c}4 \\
(3.5 \%) \\
\end{array}$ & 0 & $\begin{array}{c}12 \\
(11.2 \%) \\
(19 \%\end{array}$ & 0 & $\begin{array}{c}17 \\
(20 \%)\end{array}$ & 0 & $\begin{array}{c}15 \\
(31.9 \%) \\
\end{array}$ & 0 & $\begin{array}{c}4 \\
(26.7 \%) \\
\end{array}$ \\
\hline \multirow[t]{3}{*}{ Cefalotin } & $\mathrm{S}$ & $\begin{array}{c}23 \\
(21.9 \%)\end{array}$ & 0 & $\begin{array}{c}58 \\
(68.2 \%)\end{array}$ & $\begin{array}{c}39 \\
(28.5 \%)\end{array}$ & $\begin{array}{c}25 \\
(46.3 \%)\end{array}$ & $\begin{array}{c}95 \\
(83.3 \%)\end{array}$ & $\begin{array}{c}91 \\
(72.8 \%)\end{array}$ & $\begin{array}{c}66 \\
(61.7 \%)\end{array}$ & $\begin{array}{c}13 \\
(50 \%)\end{array}$ & $\begin{array}{c}68 \\
(80 \%)\end{array}$ & $\begin{array}{c}17 \\
(63 \%)\end{array}$ & $\begin{array}{c}14 \\
(51.9 \%)\end{array}$ & $\begin{array}{c}23 \\
(71.9 \%)\end{array}$ & $\begin{array}{c}9 \\
(60 \%)\end{array}$ \\
\hline & I & 0 & $\begin{array}{c}9 \\
(16.4 \%) \\
\end{array}$ & 0 & $\begin{array}{c}9 \\
(6.6 \%) \\
\end{array}$ & $\begin{array}{c}6 \\
(11.1 \%) \\
\end{array}$ & $\begin{array}{c}9 \\
(7.9 \%) \\
\end{array}$ & $\begin{array}{c}10 \\
(8 \%)\end{array}$ & 0 & $\begin{array}{c}4 \\
(15.4 \%) \\
\end{array}$ & 0 & 0 & $\begin{array}{c}5 \\
(10.6 \%) \\
\end{array}$ & 0 & 0 \\
\hline & $\mathrm{R}$ & $\begin{array}{c}82 \\
(78.1 \%) \\
\end{array}$ & $\begin{array}{c}46 \\
(83.6 \%) \\
\end{array}$ & $\begin{array}{c}27 \\
(31.8 \%) \\
\end{array}$ & $\begin{array}{c}89 \\
(65 \%)\end{array}$ & $\begin{array}{c}23 \\
(42.6 \%) \\
\end{array}$ & $\begin{array}{c}10 \\
(18.5 \%) \\
\end{array}$ & $\begin{array}{c}24 \\
(19.2 \%) \\
\end{array}$ & $\begin{array}{c}41 \\
(38.3 \%) \\
\end{array}$ & $\begin{array}{c}9 \\
(34.6 \%) \\
\end{array}$ & $\begin{array}{c}17 \\
(20 \%)\end{array}$ & $\begin{array}{c}10 \\
(37 \%)\end{array}$ & $\begin{array}{c}28 \\
(59.6 \%) \\
\end{array}$ & $\begin{array}{c}9 \\
(28.1) \\
\end{array}$ & $\begin{array}{c}6 \\
(40) \\
\end{array}$ \\
\hline \multirow[t]{3}{*}{ Ceftriaxone } & $\mathrm{S}$ & $\begin{array}{c}67 \\
(63.8 \%)\end{array}$ & $\begin{array}{c}10 \\
(18.2 \%)\end{array}$ & $\begin{array}{c}79 \\
(93 \%)\end{array}$ & 0 & $\begin{array}{c}54 \\
(100 \%) \\
\end{array}$ & $\begin{array}{c}85 \\
(74.5 \%)\end{array}$ & $\begin{array}{c}107 \\
(85.6 \%)\end{array}$ & $\begin{array}{c}34 \\
(31.8 \%)\end{array}$ & $\begin{array}{c}19 \\
(73.1 \%)\end{array}$ & $\begin{array}{c}62 \\
(72.9 \%)\end{array}$ & $\begin{array}{c}9 \\
(33.3 \%)\end{array}$ & $\begin{array}{c}41 \\
(87.2 \%)\end{array}$ & $\begin{array}{c}32 \\
(100 \%) \\
\end{array}$ & $\begin{array}{c}15 \\
(100 \%)\end{array}$ \\
\hline & I & $\begin{array}{c}11 \\
(10.5 \%)\end{array}$ & 0 & $\begin{array}{c}6 \\
(7.1 \%)\end{array}$ & 0 & 0 & $\begin{array}{c}9 \\
(7.9 \%)\end{array}$ & 0 & 0 & 0 & $\begin{array}{c}7 \\
(8.2 \%)\end{array}$ & 0 & 0 & 0 & 0 \\
\hline & $\mathrm{R}$ & $\begin{array}{c}27 \\
(25.7 \%)\end{array}$ & $\begin{array}{c}45 \\
(81.8 \%)\end{array}$ & 0 & $\begin{array}{c}137 \\
(100 \%)\end{array}$ & 0 & $\begin{array}{c}20 \\
(17.5 \%)\end{array}$ & $\begin{array}{c}18 \\
(14.4 \%)\end{array}$ & $\begin{array}{c}73 \\
(68.2 \%)\end{array}$ & $\begin{array}{c}7 \\
(26.9 \%)\end{array}$ & $\begin{array}{c}16 \\
(18.8 \%)\end{array}$ & $\begin{array}{c}18 \\
(66.7 \%)\end{array}$ & $\begin{array}{c}6 \\
(12.8 \%)\end{array}$ & 0 & 0 \\
\hline
\end{tabular}

Keys: $\mathrm{S}=$ Suseptible; $\mathrm{I}=$ Intermediately Susceptible and $\mathrm{R}=$ Resistance 
Bello and Bello/Carpathian Journal of Food Science and Technology, Special Issue 2020, 12(5), 81-98

\begin{tabular}{|c|c|c|c|c|c|c|c|c|c|c|c|c|c|c|c|}
\hline Antibiotic & Status & $\begin{array}{l}\ddot{\tilde{0}} \\
\dot{1}\end{array}$ & 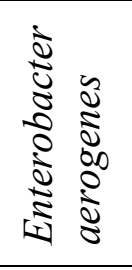 & 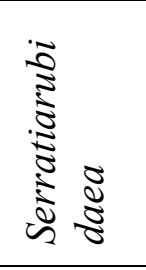 & $\begin{array}{r}0.8 \\
0 \\
5 \\
5 \\
5 \\
5 \\
5 \\
5 \\
5\end{array}$ & $\underbrace{ن}$ & 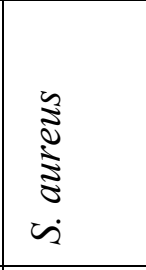 & 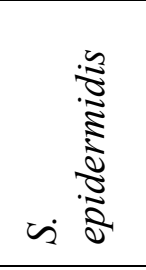 & 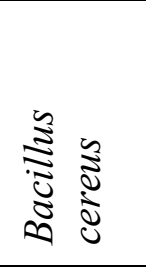 & 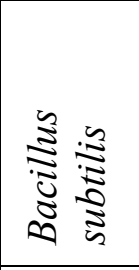 & 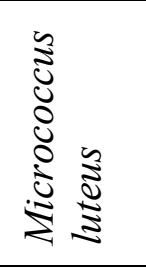 & 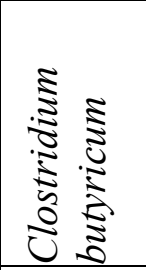 & 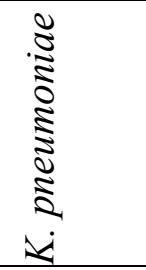 & 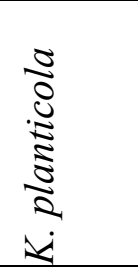 & 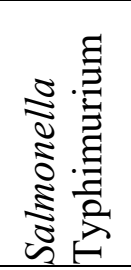 \\
\hline & & $\mathrm{n}=105$ & $\mathrm{n}=55$ & $\mathrm{n}=85$ & $\mathrm{n}=137$ & $\mathrm{n}=54$ & $\mathrm{n}=114$ & $\mathrm{n}=125$ & $\mathrm{n}=107$ & $\mathrm{n}=26$ & $\mathrm{n}=85$ & $\mathrm{n}=27$ & $\mathrm{n}=47$ & $\mathrm{n}=32$ & $\mathrm{n}=15$ \\
\hline \multirow[t]{3}{*}{ Teicoplanin } & $\mathrm{S}$ & 0 & 0 & 0 & 0 & 0 & $\begin{array}{c}30 \\
(26.3 \%)\end{array}$ & $\begin{array}{c}31 \\
(24.8 \%)\end{array}$ & 0 & 0 & $\begin{array}{c}46 \\
(54.1 \%)\end{array}$ & $\begin{array}{c}19 \\
(70.4 \%)\end{array}$ & 0 & 0 & 0 \\
\hline & $\mathrm{I}$ & 0 & 0 & 0 & 0 & 0 & $\begin{array}{c}9 \\
(7.9 \%) \\
\end{array}$ & 0 & 0 & 0 & 0 & 0 & 0 & 0 & 0 \\
\hline & $\mathrm{R}$ & $\begin{array}{c}105 \\
(100 \%)\end{array}$ & $\begin{array}{c}55 \\
(100 \%)\end{array}$ & $\begin{array}{c}85 \\
(100 \%) \\
\end{array}$ & $\begin{array}{c}137 \\
(100 \%)\end{array}$ & $\begin{array}{c}54 \\
(100 \%)\end{array}$ & $\begin{array}{c}75 \\
(65.8 \%)\end{array}$ & $\begin{array}{c}94 \\
(75.2 \%) \\
\end{array}$ & $\begin{array}{c}107 \\
(100 \%) \\
\end{array}$ & $\begin{array}{c}26 \\
(100 \%)\end{array}$ & $\begin{array}{c}39 \\
(45.9 \%) \\
\end{array}$ & $\begin{array}{c}8 \\
(29.6 \%) \\
\end{array}$ & $\begin{array}{c}47 \\
(100 \%) \\
\end{array}$ & $\begin{array}{c}32 \\
(100 \%)\end{array}$ & $\begin{array}{c}15 \\
(100 \%) \\
\end{array}$ \\
\hline \multirow[t]{3}{*}{ Vancomycin } & $\mathrm{S}$ & 0 & 0 & 0 & 0 & 0 & $\begin{array}{c}49 \\
(43 \%) \\
\end{array}$ & $\begin{array}{c}42 \\
(33.6 \%) \\
\end{array}$ & 0 & 0 & $\begin{array}{c}46 \\
(54.1 \%) \\
\end{array}$ & $\begin{array}{c}19 \\
(70.4 \%) \\
\end{array}$ & 0 & 0 & 0 \\
\hline & $\mathrm{I}$ & 0 & 0 & 0 & 0 & $\begin{array}{c}6 \\
(11.1 \%) \\
\end{array}$ & $\begin{array}{c}9 \\
(7.9 \%) \\
\end{array}$ & $\begin{array}{c}5 \\
(4 \%) \\
\end{array}$ & 0 & 0 & 0 & 0 & $\begin{array}{c}5 \\
(10.6 \%) \\
\end{array}$ & 0 & 0 \\
\hline & $\mathrm{R}$ & $\begin{array}{c}105 \\
(100 \%)\end{array}$ & $\begin{array}{c}55 \\
(100 \%)\end{array}$ & $\begin{array}{c}85 \\
(100 \%)\end{array}$ & $\begin{array}{c}137 \\
(100 \%)\end{array}$ & $\begin{array}{c}48 \\
(88.9 \%)\end{array}$ & $\begin{array}{c}56 \\
(49.1 \%)\end{array}$ & $\begin{array}{c}78 \\
(62.4 \%)\end{array}$ & $\begin{array}{c}107 \\
(100 \%)\end{array}$ & $\begin{array}{c}26 \\
(100 \%)\end{array}$ & $\begin{array}{c}39 \\
(45.9 \%)\end{array}$ & $\begin{array}{c}8 \\
(29.6 \%)\end{array}$ & $\begin{array}{c}42 \\
(83.4 \%)\end{array}$ & $\begin{array}{c}32 \\
(100 \%)\end{array}$ & $\begin{array}{c}15 \\
(100 \%)\end{array}$ \\
\hline
\end{tabular}


Higher incidence of microbial contaminants in suya had been previously reported in other places (Bakobie et al., 2017; Ribah and Manga, 2018; Ikechukwu et al., 2019). Amadi et al. (2016) also reported the occurrence of APC and TCC values of $1.39 \times 10^{5} \mathrm{cfu} / \mathrm{g}$ and $6.2 \times 10^{4}$ $\mathrm{cfu} / \mathrm{g}$ in roasted suya meat samples. Poor water and personal hygiene qualities, traditional processing techniques and exposure of suya in unhealthy environment could be attributed to this phenomenon. Similar findings on microbial biodiversity in suya had been earlier reported (Hassan et al., 2014; Orogu and Oshilim, 2017; Riba and Manga, 2018) and these underscore the level of contamination of the ready-to-eat food product.

\subsection{Identification of bacterial isolates}

One thousand and fourteen (1014) bacterial isolates were obtained. Two hundred and twenty-one (221), 226, 220 and 224 isolates were encountered from zones $\mathrm{A}, \mathrm{B}, \mathrm{C}$ and $\mathrm{D}$, respectively while 123 isolates were obtained from control samples. The isolates were characterized as E. coli, Enterobacter aerogenes, Serratia rubidaea, P. aeruginosa, C. freundii, S. aureus, S. epidermidis, Bacillus cereus, Bacillus subtilis, Micrococcus luteus, Clostridium butyricum, $K$. pneumoniae, $K$. planticola and Salmonella enterica Typhimurium (Table 3).

The presence of Salmonella enterica Typhimurium in suya is of tremendous public health concern as this puts the presumably large number of consumers at risk of gastroenteritis. Salmonella's ability to grow in food is largely dependent on storage temperature. It was recently reported by dos Santos et al. (2019) that Salmonella enterica Typhimurium is a leading cause of food poisoning cases in several countries. It is a non-specifically categorized as a zoonotic bacterium associated with animals and humans, but some strains could be invasive because of the ability to cross the intestinal wall and reach the systemic circulation (Almeida et al., 2017). The bacterium's pathogenicity ability could be attributed to its virulence factors.
C. perfringens are found in dust, soils, vegetation among other environmental media. Its presence could be attributed to growth parameters like favourable temperature. Equipment and food handlers have also been associated with contamination of food with various types of etiologic agents. Staphylococcus spp are abundant in the nose and throat as well as the skin of humans. This study agrees with the report of Uzeh et al. (2006) who isolated Pseudomonas sp., Bacillus cereus and Staphylococcus aureus from tsiresuya, a Nigerian meat product. This was also buttressed by the findings of Manyi et al. (2014) who reported Streptococcus sp., Escherichia coli, Bacillus sp., Staphylococcus aureus, Klebsiella sp. and Pseudomonas sp. in suya samples. The existence of these organisms in the suya could be attributable to the filthy environment, poor personal hygiene of the processors and retailers, the use of contaminated utensils during processing, use of contaminated materials for packaging, activities of flies as well as the addition of spices and seasonings during processing.

\subsection{Percentage frequency of bacterial isolates}

Data showed that percentage contamination of the suya samples from zones A, B, C and D were $21.80 \%, 22.29 \%, 21.70 \%$ and $22.09 \%$, respectively while the control was $12.13 \%$. There were no statistical differences among the level of bacterial contamination from zones A, $\mathrm{B}, \mathrm{C}$ and $\mathrm{D}(P>0.05)$. The data from these zones, however, showed significant differences from the control $(P<0.05)$ (Figure 1). The most occurred bacterium from the suya samples in zone A was $P$. aeruginosa with percentage occurrence of $13.58 \%$ while the lowest was Salmonella enteric Typhimurium with 1.81\% (Figure 2). In all, the highest occurred bacterial species was $P$. aeruginosa $(137 ; 13.51 \%)$ while the lowest was Salmonella enteric Typhimurium (15; 1.48\%) (Figure 3).

The results of this study differ from a study by Onuorah et al. (2015) who reported Escherichia coli $(34.3 \%)$ as the most frequent 
while Streptococcus pyogenes $(8.6 \%)$ had the lowest. $P$. aeruginosa is widely spread in nature especially in the soil, water, on plants and can easily contaminate food products. This finding agrees with the study of Egbebi and Muhammad (2016) who reported $P$. aeruginosa as the most predominant organism in their study. Higher percentage of organisms had earlier been reported (Kigigha et al., 2017; Orogu and Oshilim, 2017). There may be a possible outbreak of food poisoning and/or food-borne infections due to the consumption of contaminated suya meat, if appropriate quality control measures are not put in place. This may lead to serious economic and public health problems.

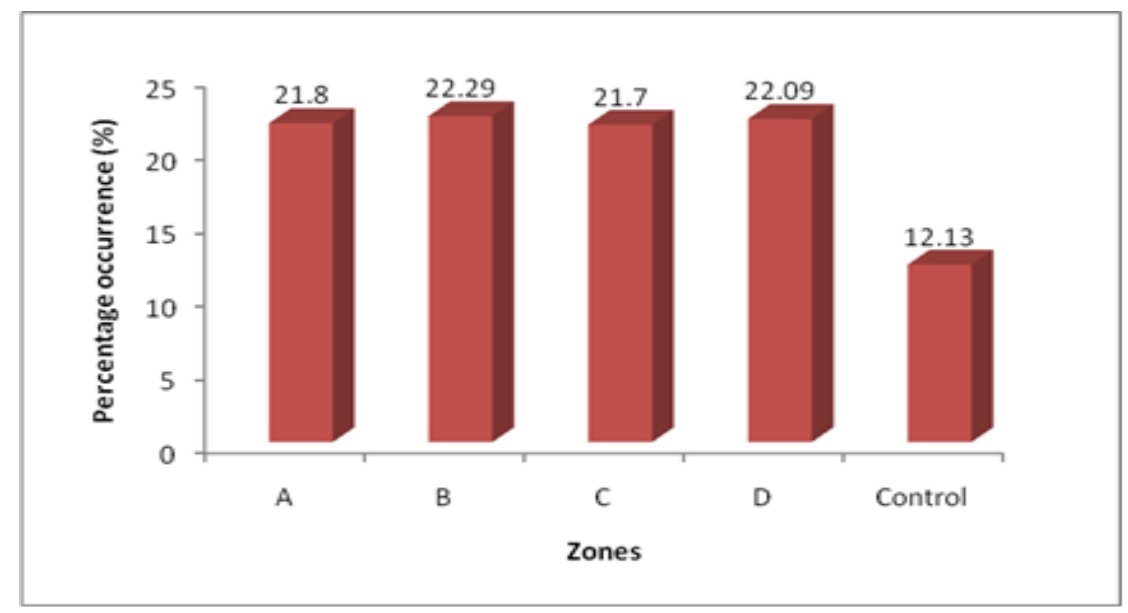

Figure 1. Percentage occurrence of bacteria in suya from different zones of Ogun State, Nigeria. Data were statistically analysed at $95 \%$ level of confidence $(\mathrm{P}<0.05)$ using ANOVA and paired wise sampling t-test.

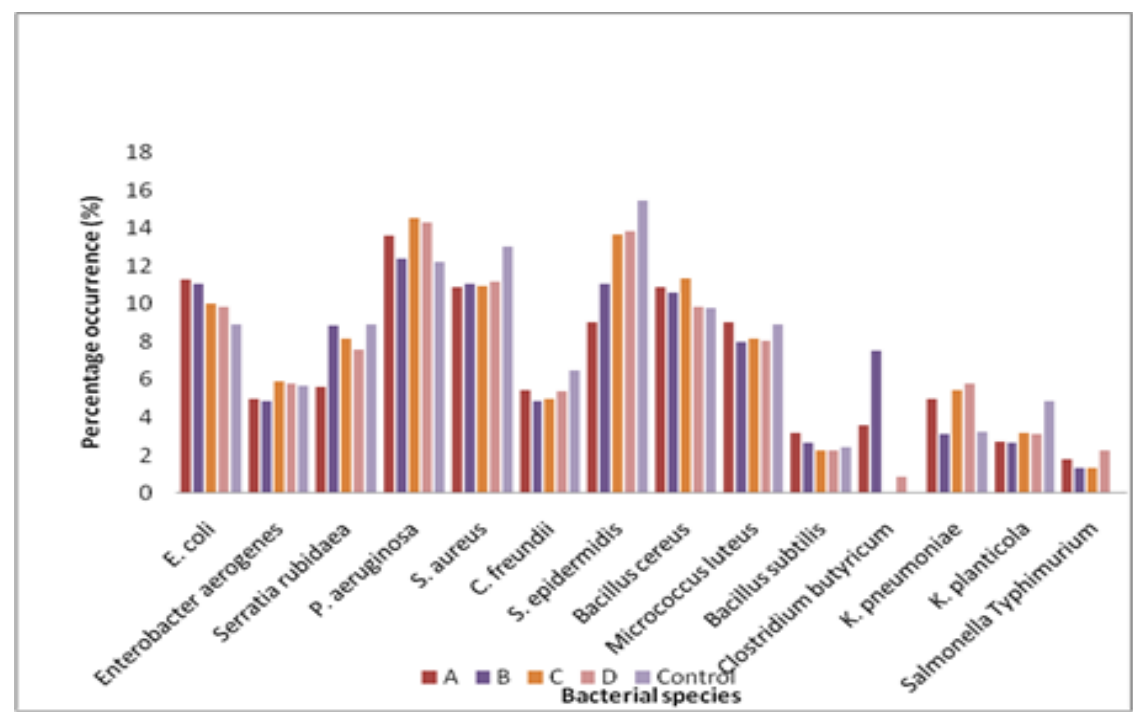

Figure 2. Percentage occurrence of individual bacterial species in suya from different geopolitical zones in Nigeria.

\subsection{The antibiotic susceptibility patterns of bacterial isolates}

For the purpose of simplification, a standardized, threshold-based assessment scheme has been introduced in which the degree of the effectiveness of the antibiotics investigated in this study is characterized as "susceptible (S)," "intermediate (I)," or "resistant (R)," based on their inbibition zones. The isolates showed varying degrees of 
sensitivity to the antibiotics and are classified based on their zones of inhibitions (Table 4). Varying percentages including $11.20 \%$, $15.09 \%, 9.86 \%, \quad 18.05 \%, 21.10 \%, 34.81 \%$, $30.57 \%, 36.19 \%, 41.50 \%, 36.70 \%, 43.49 \%$, $52.86 \%, 54.83 \%, 68.64 \%, 82.15 \%$ and $86.69 \%$ of the isolated strains exhibited resistance to doxycycline, chloramphenicol, trimethoprim/sulfamethoxazole, gentamicin, tetracycline, ciprofloxacin, ampicillin, cefriaxone, colistin, erythromycin, cefalotin, penicillin G, rifampicin, nalidixic acid, vancomycin and teicoplanin, respectively (Figure 4).
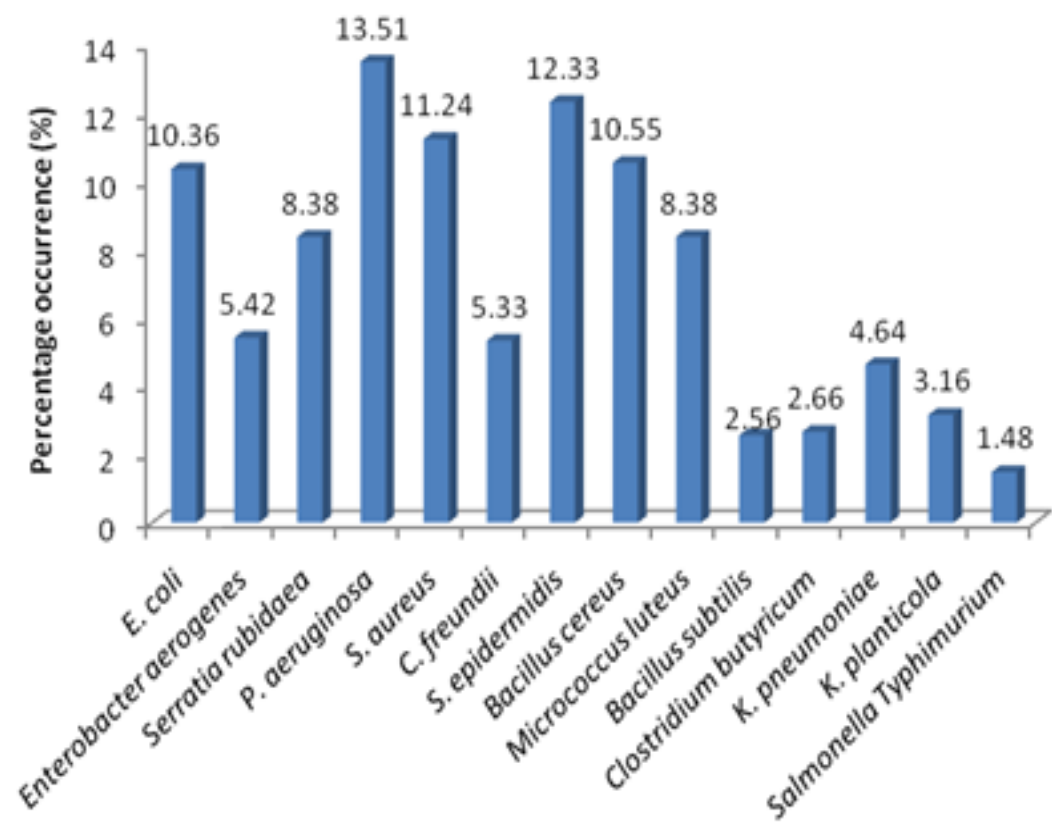

Bacterial species

Figure 3. Cumulative percentage frequency of bacterial species from suya in Nigeria

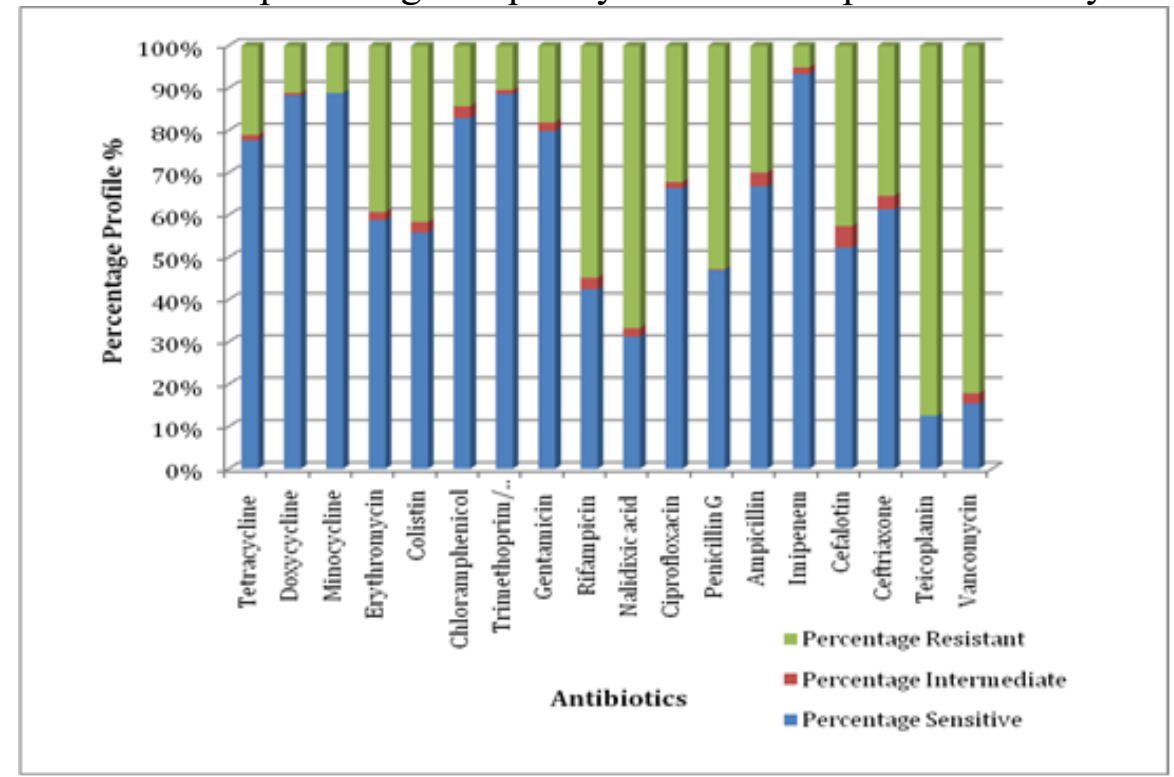

Figure 4. Cumulative percentage susceptibility and resistance profile of bacterial isolates from suya meat samples in Nigeria. 
The findings on the antibiotic resistance of bacteria in this study deviated from the result of Barber et al. (2018) who reported that all $E$. coli was resistant to chloramphenicol and streptomycin. Nutanbala et al. (2011) reported the sensitivity of $E$. coli to ciproflaxain which is in line with the finding of this study. Ciprofloxacin belong to the fluoroquinolone class of antibiotics and has been known to have excellent activities against Gram-negative and Gram-positive bacteria such as $E$. coli and $S$. aureus, respectively (Cohen et al., 2017). The report of Sani et al. (2012) also buttressed the sensitivity of $S$. aureus to the fluoroquinolones. However, nalidixic acid exerted poor antimicrobial effects on the isolates as $68.64 \%$ of the bacterial isolates exhibited resistance to it in this study. The mechanism of action of the fluoroquinolones is the inhibition of bacterial DNA gyrase responsible for DNA replication and transportation (Moore, 2015). Ampicillin also inhibited the growth of $62.53 \%$ of the bacterial isolates in this study.

Minocycline, doxycycline and tetracycline exerted antimicrobial potency against $89 \%$, $88.20 \%$ and $77.60 \%$ of the bacterial isolates. These antibiotics belong to the class tetracylines which inhibit protein synthesis by preventing the attachment of aminoacyl-tRNA to the ribosomal acceptor (A) site. Their high potency against bacterial isolates could be attributed to the fact that they are broadspectrum agents. However, Mhondoro et al. (2019) reported high percentages of resistance to this class of antibiotics in their study. The penicillin-based antibiotics, such as the imipenem, act by binding to and inactivating penicillin-binding proteins (PBPs) located on the inner membrane of a bacterial cell wall. The strength and rigidity of the bacterial cell wall are affected by the inactivation of PBPs which interferes with the cross-linkage of peptidoglycan chains. This brings about the interruption of synthesis of bacterial cell wall which weakens the bacterial cell wall and results to cell lysis (Niwa et al., 2016).

Cefalotin and Ceftriaxone belong to the first and third generations of cephalosporins, respectively, and they possess the same mechanism of action like the penicillin-based antibiotics. The peptidoglycan layer of bacterial cell walls is disrupted by these antibiotics through competitive inhibition on penicillinbinding proteins (Moore, 2015). More than half $(62.53 \%$ and $53.35 \%)$ of the isolates were sensitive to cefalotin and ceftriaxone, respectively. This is in line with the findings of Sani et al. (2012) and Page (2012) who also reported the sensitivity of similar bacterial isolates to the cephalosporins.

Trimethoprim/sulfamethoxazole and colistin inhibited the growth of $83.33 \%$ and $55.60 \%$ of the bacterial isolates, respectively. Cefalotin and ceftriaxone inhibit cell wall synthesis through the inhibition of $\beta$-lactamase (Bello et al., 2019). Erythromycin exerted antimicrobial potency against $54.90 \%$ of the bacterial isolates in this study which was also buttressed by the report of Hardman et al. (2017) where over half of the organisms isolated were sensitive to same class of antibiotics. Erythromycin is a macrolide-based antibiotic which reversibly binds to the $50 \mathrm{~s}$ ribosomal subunit to inhibit synthesis of protein (Moore, 2015).

Gentamicin belongs to the aminoglycoside class of antibiotics. The high potency exerted by the gentamicin against bacterial isolates could be associated with the mechanism of action of this class of antibiotics which enables it to bind irreversibly to the $16 \mathrm{~S}$ rRNA subunit of the $30 \mathrm{~S}$ ribosome, resulting to inhibition of bacterial protein synthesis. This finding is supported by the reports of Barber et al. (2018), Mhondoro et al. (2019) and Breijyeh et al. (2020). A high percentage of the bacterial isolates $(87.50 \%)$ were sensitive to chloramphenicol. Chloramphenicol belongs to the phenicol class whose mode of action is to interfere with bacterial protein synthesis.

The production of chloramphenicol acetyltransferase (CAT) is responsible for the resistance of bacteria to chloramphenicol while some resistance occur as a result of inability of certain bacteria to reach their target sites. 
Only $15.39 \%$ and $12.43 \%$ of the bacteria isolated in this study were sensitive to vancomycin and teicoplanin, respectively. This is attributed to the fact that vancomycin and teicoplanin are narrow spectrum and exert very weak action against many Gram-negative bacteria. Vancomycin and teicoplanin belong to the glycopeptides and their modes of action are same as the $\beta$-lactam antibiotics. However, glycopepetides differ from $\beta$-lactams in that they interact with different molecular targets as they bind to acyl-D-alanyl-D-alanine in peptidoglycan and, hence, inhibit the function of glycosyltranfereases in susceptible bacteria. The hydrophilic antibiotics like $\beta$-lactams pass through porins, and glycopeptides cannot cross the outer membrane due to their structures that hinder it from using any of these passages (Breijyeh et al., 2020).

\section{Conclusions}

The microbial loads encountered in suya meat from this study were at the borderline based on the microbiological guidelines for ready-to-eat food products. The study revealed the presence and distribution of multidrugresistant food pathogens in the food product which is of tremendous public health concern.

\section{References}

Almeida, F., Medeiros, M.I.C., dos Prazeres, R.D., Allard, M.W., Falcao, J.P. (2017). Molecular characterization of Salmonella Typhimurium isolated in Brazil by CRISPR-MVLST. Journal of Microbiology Methods 133, 55-61.

Amadi, L.O., Singabele, F.O., Elechi, R.,Ngerebara, N.N. (2016). Bacterial status and antibacterial susceptibility profiles of selected pathogens associated with suya meat samples purchased in Bori metropolis, Rivers State, Nigeria. International Research Journal of Public and Environmental Health 3 (2), 14-19.

American Public Health Assessment, APHA (1992). Compendium of method for the microbiological examination of foods, (3rd ed.) American Public Health Assessment.
In: C. Vanderzant, and D. F. Splitsloesser (Eds.). Michigan, USA. Retrieved on 20/03/2020

fromhttp://lib.ugent.be/catalog/rug01:00032 2598

Apata, E.S., Kuku, I.A., Apata, O.C.,Adeyemi K.O. (2013). Evaluation of Suya(Tsire) An Intermediate Moisture Meat Product in Ogun State, Nigeria. Journal of Food Research 2 (1), 87 -93.

Association of Official Analytical Chemist, AOAC (2000). Official methods of analyses (15th Ed), Association of Official Analytical Chemist, Washington D.C, 808, 831-835, 1113.

Bakobie, N., Addae, A.S., Duwiejuah, A.B., Cobbina S.J., Miniyila, S. (2017). Microbial profile of common spices and spice blends used in Tamale, Ghana .International Journal of Food Contamination 4, 10-12.

Barber, L.I, Obinna-Echem, P.C.,Amadi S.C. (2018). Microbiological quality and antibiotic sensitivity of potential pathogens isolated from meat product (suya) sold in Rivers State University and its environs. International Journal of Biotechnology and Food Science6 (4), 67-76.

Bello, O.O., Oni, M.O., Bello, J.O., Bello, T.K. (2019). Incidence of extended-spectrum beta-lactamase producing bacteria in salad vegetables in Ondo city, Nigeria. Asian Food Science Journal 9 (1), 1-14

Breijyeh, Z., Jubeh, B.,Karaman, R. (2020). Resistance of Gram-negative bacteria to current antibacterial agents and approaches to resolve it. Molecules 25, 1340.

Centre for Food Safety (2014). Microbiological Guidelines for Food (For ready-to-eat food in general and specific food items). The Centre for Food Safety, Food and Environmental Hygiene Department, Queensway, Hong Kong.

Clinical Laboratory Standards Institute (CLSI), (2016) "Performance standards for antimicrobial susceptibility testing," NCCLS approved standard M100-S14, 
Wayne, PA. USA, 11 (2): pp. 298-102, 2016.

Cohen, J., Powderly, W.G., Opal, S.M. (2017). Infectious diseases. 4ed. Elsevier Ltd. ISBN 978-0-7020-6285-8.

Cowan, S.T., Steel, K.J. (1985). Manual for the identification of bacteria. Cambridge University Press, Verlage, New York, p. 502.

dos Santos, A.M.P., Ferrari, R.G., ConteJunior, C.A. (2019). Virulence Factors in Salmonella Typhimurium: The Sagacity of a Bacterium. Current Microbiology 76 (6), 762-773.

Egbebi, A.O., Seidu K.T. (2011). Microbiological evaluation of suya (dried smoked meat) sold in Ado and Akure, South West Nigeria. European Journal of Experimental Biology 1 (4), 1-5.

Egbebi, O.A., Muhammad, A.A. (2016). Microbiological analysis of ready-to-eat suya meat sold in Owo, Ondo State. International Journal of Innovative Biochemistry and Microbiology Research 4 (2), 11-15.

El-Hassan, F.I, Umar, F.S, Yahaya, A., Ali, M. (2018). Microbial quality assessment of processed meat product (tsire) sold within Wudil town, Wudil Local Government Area, Kano State, Nigeria. Modern Application in Pharmacy and Pharmacology 2(2), 1-7

Grimont, P.A.D., Weill, F.X. (2007). Antigenic formulae of the Salmonella serovars. Institut Pasteur \&WHO Collaborating Centre for Reference and Research on Salmonella, Paris, France.

Guibourdenche, M., Roggentin, P., Mikoleit, M. Fields, P.I., Bockemuhl, J., Grimont, P.A., Weill, F.X. (2010). Supplement 20032007 (No. 47) to the White-Kauffmann-Le Minor scheme. Research in Microbiology 161, 26-29.

Hardman, B., Hunt, D.J., Mojaab, D., Naor, A. (2017). Sub-lethal gentamicin treatment of Escherichia coli UB1005 induces the release of soluble factors that reduce susceptibility to $\mathrm{t} 7$ bacteriophage infection.
Journal of Experimental Microbiology and Immunology 21, 128-133.

Hassan, I.A., Emun, H.O., Adekunle, E.O. (2014). Microbial quality of ready-to-eat barbecue meat (suya) sold on the streets of Lagos State. International Journal of Advances in Pharmacy, Biology and Chemistry 3(4), 973-982.

Ikechukwu, N.M., Kosisochukwu, A.C., Chukwuebuka, I.F., Ogechi, N.I., Chisom, O.C., Chukwufumnanya, E.C. (2019). Bacteriological analysis of ready-to-eat barbecue meat (suya) sold in Yenagoa, Bayelsa State Nigeria. International Journal of Microbiology and Biotechnology 4(1), 24-28.

Kigigha, L.T., Berezi, J., Izah, S.C. (2017). Bacteriological quality assessment of meat pie sold in Yenagoa Metropolis, Nigeria. EC Nutrition 6(6), 189-195.

Manyi, M.M., Idu, O.F., Ogbonna, I.O. (2014). Microbiological and parasitic quality of Suya (roasted beef) sold in Makurdi, Benue State, Nigeria. African Journal of Microbiology Research 8 (35), 3235-3242.

Mhondoro, M., Ndlovu, N., Bangure, D. TsitsiJuru, T., Gombe, N.T., Shambira, G., Nsubuga, P., Tshimanga, M. (2019). Trends in antimicrobial resistance of bacterial pathogens in Harare, Zimbabwe, 2012-2017: a secondary dataset analysis. BMC Infectious Diseases 19, 746.

Moore, D. (2015). Antibiotic Classification and Mechanism. Accessed on 20/03/2020 at https://www.orthobullets.com/basicscience/9059/antibiotic-drugs.

Niwa, T., Morimoto, M., Hirai, T., Hata, T., Hayashi, M., Imagawa, Y. (2016). Effect of penicillin-based antibiotics, amoxicillin, ampicillin, and piperacillin, on drugmetabolizing activities of human hepatic cytochromes P450. The Journal of Toxicological Sciences 41(1), 143-6.

Nutanbala, N.G., Hiren, R.T., AlpshPur, P.G., Tejas, K.P., Tripathi, C.B. (2011). Antibiotic sensitivity profile of bacterial pathogens in postoperative wound infections at a tertiary care hospital in 
Gujarat, India. Journal of Pharmacology and Pharmacotherapeutics 2(3), 158-164.

Nwakanma, C., Unachukwu, M.N.,Momoh, O.R. (2015). Bacteriological examination of suya meat sold in Enugu Metropolis. World Journal of Pharmaceutical Research 4(12), 61-70.

Olayinka, T.J., Sani J. (2014). Microblological quality assessment of meat samples sold in Kaura Namoda. International Conference on Earth, Environment and Life Sciences (EELS-2014) Dubai (UAE).

Onuorah, S.O.I., Odibo F., Orji M. (2015). An assessment of the bacteriological quality of tsire-suya (grilled beef) sold in Awka, Nigeria. American Journal of Life Science Research 3(4), 267-292.

Orogu, J.O., Oshilim A.O. (2017). Comparative study of bacteriological analysis in hawked suya meat and suya meat on a Barbeque stand. Journal of Microbiology Research 3(1), 005-008.

Page, M.G.P. (2012). Beta-Lactam Antibiotics. In: Dougherty T., Pucci M. (eds) Antibiotic Discovery and Development. Springer, Boston, MA ISBN 978-1-4614-1399-8.

Ribah, M.I., Manga, S.S. (2018). Prevalence of Staphylococcus aureus in some street vended ready-to-eat meat products in Birnin-Kebbi metropolis: A potential food safety threat. Journal of Environmental Toxicology and Public Health 3, 25-29.

Sani, R.A., Garba, S.A., Oyewole, O.A., Ibrahim, A. (2012). Antibiotic resistance profile of gram positive bacteria isolated from wound infections in Minna, Bida, Kontagora and Suleja Area of Niger State. Journal of Health Sciences 2(3), 19-22.

World Health Organisation, WHO (2014).

World malaria report. Syrian Arab Republic Annual Report. 182-210.

\section{Acknowledgement}

The effort of Late Prof. Afolabi Oluwadun, who read and corrected the final draft of this manuscript, is hereby appreciated. 